\title{
Inverse transport modeling of volcanic sulfur dioxide emissions using large-scale simulations
}

\author{
Yi Heng ${ }^{1,2, a}$, Lars Hoffmann ${ }^{1}$, Sabine Griessbach ${ }^{1}$, Thomas Rößler ${ }^{1}$, and Olaf Stein ${ }^{1}$ \\ ${ }^{1}$ Forschungszentrum Jülich, Jülich Supercomputing Centre (JSC), Jülich, Germany \\ ${ }^{2}$ Forschungszentrum Jülich, Institute of Energy and Climate Research - Tropospheric Research (IEK-8), \\ Jülich, Germany \\ ${ }^{a}$ now at: School of Chemical Engineering and Technology, Sun Yat-sen University, Guangzhou, China \\ Correspondence to: Yi Heng (y.heng@fz-juelich.de, hengyi@mail.sysu.edu.cn)
}

Received: 3 August 2015 - Published in Geosci. Model Dev. Discuss.: 21 October 2015

Revised: 3 April 2016 - Accepted: 7 April 2016 - Published: 2 May 2016

\begin{abstract}
An inverse transport modeling approach based on the concepts of sequential importance resampling and parallel computing is presented to reconstruct altitude-resolved time series of volcanic emissions, which often cannot be obtained directly with current measurement techniques. A new inverse modeling and simulation system, which implements the inversion approach with the Lagrangian transport model Massive-Parallel Trajectory Calculations (MPTRAC) is developed to provide reliable transport simulations of volcanic sulfur dioxide $\left(\mathrm{SO}_{2}\right)$. In the inverse modeling system MPTRAC is used to perform two types of simulations, i.e., unit simulations for the reconstruction of volcanic emissions and final forward simulations. Both types of transport simulations are based on wind fields of the ERA-Interim meteorological reanalysis of the European Centre for Medium Range Weather Forecasts. The reconstruction of altitude-dependent $\mathrm{SO}_{2}$ emission time series is also based on Atmospheric InfraRed Sounder (AIRS) satellite observations. A case study for the eruption of the Nabro volcano, Eritrea, in June 2011, with complex emission patterns, is considered for method validation. Meteosat Visible and InfraRed Imager (MVIRI) near-real-time imagery data are used to validate the temporal development of the reconstructed emissions. Furthermore, the altitude distributions of the emission time series are compared with top and bottom altitude measurements of aerosol layers obtained by the Cloud-Aerosol Lidar with Orthogonal Polarization (CALIOP) and the Michelson Interferometer for Passive Atmospheric Sounding (MIPAS) satellite instruments. The final forward simulations provide detailed spatial and temporal information on the $\mathrm{SO}_{2}$ distributions of the
\end{abstract}

Nabro eruption. By using the critical success index (CSI), the simulation results are evaluated with the AIRS observations. Compared to the results with an assumption of a constant flux of $\mathrm{SO}_{2}$ emissions, our inversion approach leads to an improvement of the mean CSI value from 8.1 to $21.4 \%$ and the maximum CSI value from 32.3 to $52.4 \%$. The simulation results are also compared with those reported in other studies and good agreement is observed. Our new inverse modeling and simulation system is expected to become a useful tool to also study other volcanic eruption events.

\section{Introduction}

Observing trace gases and ash released by volcanic eruptions is important for various reasons. Most notably, sulfate aerosols formed by oxidation of $\mathrm{SO}_{2}$ have a significant impact on radiative forcing and are a natural cause for climate variations (Lamb, 1970; Robock, 2000; Solomon et al., 2011). Strong volcanic eruptions inject $\mathrm{SO}_{2}$ directly into the lower stratosphere. However, more complex transport processes such as the Asian monsoon circulation have also been investigated (Bourassa et al., 2012; Fromm et al., 2013; Vernier et al., 2013). Further motivation to monitor the dispersion of volcanic emissions is to prevent aircraft from entering potentially dangerous regions, i.e., flight corridors containing high loads of volcanic ash (Casadevall, 1994; Carn et al., 2009; Prata, 2009; Brenot et al., 2014). In practice, the presence of volcanic $\mathrm{SO}_{2}$ can often be considered as a good proxy for the presence of volcanic ash (Sears et al., 
2013), although in some cases different transport directions of $\mathrm{SO}_{2}$ and ash were also observed because of different injection altitudes and vertical wind shear (Moxnes et al., 2014).

Satellite instruments are well suited to observe trace gases and aerosols on a global scale and to provide long-term records. Together, volcanic $\mathrm{SO}_{2}$ and sulfate aerosols provide excellent tracers to study atmospheric transport processes. In order to further improve the quality of available satellite data, e. g., to perform more effectual suppression of interfering background signals, new detection algorithms for volcanic emissions for European Space Agency (ESA) and National Aeronautics and Space Administration (NASA) satellite experiments have been developed and are used in this study (Griessbach et al., 2012, 2014; Hoffmann et al., 2014; Griessbach et al., 2015). However, satellite observations are often limited in temporal and spatial resolution due to their measurement principles. Therefore, atmospheric models are indispensable to study transport processes. In particular, Lagrangian particle dispersion models enable studies of transport and mixing of air masses based on the trajectories of individual air parcels. Widely used models are the Flexible Particle (FLEXPART) model (Stohl et al., 2005), the Hybrid Single-Particle Lagrangian Integrated Trajectory (HYSPLIT) model (Draxler and Hess, 1998), the Lagrangian analysis tool (LAGRANTO) (Wernli and Davies, 1997), and the Numerical Atmospheric-dispersion Modeling Environment (NAME) (Jones et al., 2007). Recently, Massive-Parallel Trajectory Calculations (MPTRAC), a new Lagrangian transport model that is designed for large-scale simulations on state-ofthe-art supercomputers, was developed at the Jülich Supercomputing Centre. A detailed description of MPTRAC and a comparison of the results of transport simulations for three volcanic emission events by means of different, freely available meteorological data products can be found in Hoffmann et al. (2016).

Suitable initializations of the trajectory model, namely, the altitude- and time-resolved emission data, are crucial for accurate and reliable simulations of the transport of volcanic $\mathrm{SO}_{2}$ emissions. However, emissions usually can only be reconstructed indirectly, for instance, by empirical estimates from weather radar measurements (Lacasse et al., 2004), or by using satellite data (Theys et al., 2013; Clarisse et al., 2014; Hoffmann et al., 2016). We refer to previous work (Eckhardt et al., 2008; Stohl et al., 2011; Kristiansen et al., 2012, 2015) on inverse transport modeling techniques in the context of estimating volcanic emissions. Those studies used an analytical inversion algorithm, based on Seibert (2000), for the reconstruction of volcanic ash or $\mathrm{SO}_{2}$ emission rates. The inversion approach was applied to several case studies such as the 2010 Eyjafjallajökull and the 2014 Kelut eruptions. With respect to the mathematical setting, the estimation task was formulated as a linear inverse problem. A Tikhonov-type regularization method (Tikhonov and Arsenin, 1977; Seibert, 2000) was used to resolve the ill posedness of the inverse problem. The objective function defined for the minimization problem not only quantifies the misfit between model values and observations, but also enforces smoothness of the solution. Several parameters such as the matrix of model sensitivities of observations to source terms and the regularization parameters that tune the smoothness of the solution needed to be provided a priori. Other work such as Flemming and Inness (2013) used satellite retrievals of $\mathrm{SO}_{2}$ total columns to estimate initial conditions for subsequent $\mathrm{SO}_{2}$ plume forecasts by applying the Monitoring Atmospheric Composition and Climate (MACC) system (Stein et al., 2012), which is an extension of the 4D-Var system of the European Centre for Medium Range Weather Forecasts (ECMWF).

In this paper, we present a new inverse modeling and simulation system that can be used to establish reliable transport simulations for volcanic $\mathrm{SO}_{2}$ emissions with available meteorological data and satellite observations. The core of the system, an inversion approach based on the concept of sequential importance resampling (Gordon et al., 1993), is used to reconstruct altitude-dependent time series of volcanic emissions. It assumes that the volcanic $\mathrm{SO}_{2}$ emissions distribute not only vertically above the location of the volcano (typically from 0 up to $30 \mathrm{~km}$ altitude), but also over a period of time (typically for a couple of days). For the numerical computation, we discretized the emission domain as finely as technically feasible in order to reveal local details of the $\mathrm{SO}_{2}$ emissions at high temporal and spatial resolution. This way, we expect to obtain more reliable simulation results. The fine discretization increases demands on computing capabilities. Nevertheless, the resulting large computational effort can be handled by our solution approach that is well suited for massive-parallel supercomputing architectures. The timeand altitude-dependent volcanic emission rates are estimated iteratively by performing a large number $(>10000)$ of unit simulations in parallel with MPTRAC. A distinct advantage of this approach is that the proposed inverse modeling and simulation system requires no a priori information on the emissions and does not require the calculation of the full source-receptor matrix. However, an assumption of the total $\mathrm{SO}_{2}$ mass is needed. We considered a much finer discretization for the unknown time- and altitude-dependent emission function $-250 \mathrm{~m}$ in altitude and $1 \mathrm{~h}$ in time in our case, about $2-3 \mathrm{~km}$ and more than $6 \mathrm{~h}$ in the case of Flemming and Inness (2013), and 19 vertical layers stacked up to $12.3 \mathrm{~km}$ altitude and $3 \mathrm{~h}$ time intervals in the case of Stohl et al. (2011). We did not find a need to solve the ill-posed inverse problem by means of a Tikhonov or smoothing constraint. Furthermore, the critical success index (CSI) was used here for the first time to evaluate the goodness-of-fit of the forward simulations and to estimate the importance weights of the time- and altitude-dependent $\mathrm{SO}_{2}$ emission distribution. This way, we were able to provide relative distributions of the emissions in a two-dimensional view (in time and altitude) and its local details at relatively high (or even unprecedented) temporal and spatial resolution. 
This paper is organized as follows: we first briefly introduce the Lagrangian transport model MPTRAC, the ERAInterim meteorological data product, the Atmospheric InfraRed Sounder (AIRS) satellite observations, and other validation data sets in Sect. 2. In Sect. 3, we present the concept of our new inverse modeling and simulation system, which uses an efficient parallel strategy for the reconstruction of volcanic emissions and to establish reliable $\mathrm{SO}_{2}$ transport simulations. In Sect. 4, we focus on a case study of the Nabro volcano, Eritrea, whose eruption started on 12 June 2011 and lasted several days. First, the reconstructed altitude-resolved time series of volcanic emissions are discussed and validated with Meteosat Visible and InfraRed Imager (MVIRI) infrared imagery and Cloud-Aerosol Lidar with Orthogonal Polarization (CALIOP) and Michelson Interferometer for Passive Atmospheric Sounding (MIPAS) aerosol measurements. Second, forward simulation results based on these initial conditions are evaluated with the AIRS satellite observations. A comparison of the simulations results with those reported in the studies of Theys et al. (2013) and Clarisse et al. (2014) is also included. Our conclusions are given in the final section.

\section{Transport model and satellite data products}

\subsection{MPTRAC}

In this study we make use of the Lagrangian transport model MPTRAC (Hoffmann et al., 2016) for the forward simulations. MPTRAC calculates the trajectories for large numbers of air parcels to represent the advection of air. The kinematic equation of motion is solved with the explicit midpoint method (Hoffmann et al., 2016). Diffusion and subgrid-scale wind fluctuations are simulated following the approach of the FLEXPART model (Stohl et al., 2005; Hoffmann et al., 2016). A hybrid-parallelization scheme based on the Message Passing Interface (MPI) and Open MultiProcessing (OpenMP) is implemented in MPTRAC. The MPI distributed memory parallelization is applied to facilitate ensemble simulations by distributing the ensemble members on the different compute nodes of a supercomputer. Trajectory calculations of an individual ensemble member are distributed over the cores of a compute node by means of the OpenMP shared memory parallelization. This implementation enables rapid forward simulations for ensembles with large numbers of air parcels (typically on the order of $10^{2}$ to $10^{4}$ members per ensemble, with $10^{6}$ to $10^{8}$ air parcels per ensemble member). Moreover, MPTRAC provides efficient means for model output and data visualization. For further details we refer to the work of Hoffmann et al. (2016).

External meteorological data are a prerequisite for the trajectory calculations with MPTRAC. We use the latest global atmospheric reanalysis produced by ECMWF, namely, the ERA-Interim data product (Dee et al., 2011). A large vari- ety of 3-hourly surface parameters and 6-hourly upper-air parameters that cover the troposphere and stratosphere are included in the data product. Here, the ERA-Interim standard data on a $1^{\circ} \times 1^{\circ}$ longitude-latitude grid are applied. The altitude coverage ranges from the surface to $0.1 \mathrm{hPa}$ with 60 model levels. The vertical resolution in the upper troposphere and lower stratosphere (UT/LS) region varies between 700 and $1200 \mathrm{~m}$. The 6-hourly temporal resolution corresponds to data assimilation cycles at 00:00, 06:00, 12:00, and 18:00 UTC. A discussion of the analysis increments of the ERA-Interim data, being a figure of merit for the data quality, can be found in Dee et al. (2011). Including a case study for the Nabro eruption, Hoffmann et al. (2016) showed that ERA-Interim data provided good performance in the Lagrangian transport simulations of volcanic $\mathrm{SO}_{2}$ with MPTRAC in comparison with three other meteorological data products.

\subsection{AIRS}

For inversely estimating the volcanic emissions and for validating the simulation results, we use satellite observations of volcanic $\mathrm{SO}_{2}$ obtained by the AIRS instrument (Aumann et al., 2003; Chahine et al., 2006) aboard NASA's Aqua satellite. Aqua is in a nearly polar, sun-synchronous orbit with Equator crossing at 01:30 and 13:30 LT (local time). Scans in the across-track direction are carried out by means of a rotating mirror. Each scan consists of 90 footprints that correspond to $1765 \mathrm{~km}$ distance on the ground surface. Two adjacent scans are separated by $18 \mathrm{~km}$ along-track distance. While the AIRS footprint size is $13.5 \mathrm{~km} \times 13.5 \mathrm{~km}$ at nadir, it is $41 \mathrm{~km} \times 21.4 \mathrm{~km}$ at the scan extremes. Thermal infrared spectra (3.7 to $15.4 \mu \mathrm{m}$ ) for more than 2.9 million footprints are measured by AIRS per day.

Volcanic $\mathrm{SO}_{2}$ can be detected efficiently from infrared radiance spectra based on brightness temperature differences (BTDs) (e. g., Karagulian et al., 2010; Clarisse et al., 2013). Here we use the BTD identified by Hoffmann et al. (2014) to detect $\mathrm{SO}_{2}$ from AIRS 7.3 $\mu \mathrm{m}$ radiance measurements and apply their derived $\mathrm{SO}_{2}$ index (SI) in our study. False detections related to scenes with low brightness temperatures due to deep convective clouds are filtered based on the detection scheme of Hoffmann and Alexander (2010). Hoffmann et al. (2014) demonstrated that their SI is better capable of suppressing background signals than the NASA operational SI and is well suited to trace even low $\mathrm{SO}_{2}$ concentrations over long time periods. The AIRS data product provides $\mathrm{SO}_{2}$ indices for atmospheric columns; i.e., no vertical profile information on the $\mathrm{SO}_{2}$ distributions is directly available. However, radiative transfer calculations showed (Hoffmann and Alexander, 2009; Hoffmann et al., 2016) that the SI of Hoffmann et al. (2014) is most sensitive to $\mathrm{SO}_{2}$ layers at about 8 to $13 \mathrm{~km}$ altitude. Besides, nearly global coverage can only be achieved every $12 \mathrm{~h}$ and there is information lacking for uncovered regions between the satellite scans. Note that the 
AIRS data product considered here has low noise, i.e., about $0.14 \mathrm{~K}$ at $250 \mathrm{~K}$ scene temperature.

\subsection{Validation data sets}

For validation of the temporal development of the reconstructed emissions, we consider infrared (IR; $11.5 \mu \mathrm{m}$ ) and water-vapor $(\mathrm{WV} ; 6.4 \mu \mathrm{m})$ radiance data products from the MVIRI aboard Eumetsat's Meteosat-7 (Indian Ocean Data Coverage, IODC). ${ }^{1}$ MVIRI provides radiance images in three spectral bands from the full Earth disc at $5 \mathrm{~km} \times 5 \mathrm{~km}$ resolution (sub-satellite point) every $30 \mathrm{~min}$. The MVIRI IR band overlaps with a spectral window region and is used for imaging surface and cloud top temperatures at day and night. The MVIRI WV absorption band is mainly used for determining the amount of water vapor in the upper troposphere. This band is opaque if water vapor is present, but transparent if the air is dry. The WV band can effectively be used to detect volcanic emissions in the upper troposphere because emissions from lower altitudes are blocked by water vapor absorption.

To verify the altitude distribution of the volcanic emissions we consider aerosol measurements from the CALIOP instrument aboard the Cloud-Aerosol Lidar and Infrared Pathfinder Satellite Observations (CALIPSO) satellite (Winker et al., 2010). ${ }^{2}$ The spatial resolution of the CALIOP data is $1.67 \mathrm{~km}$ (horizontal) $\times 60 \mathrm{~m}$ (vertical) at 8 to $20 \mathrm{~km}$ altitude. We also consider aerosol top and bottom altitude measurements from the Michelson Interferometer for Passive Atmospheric Sounding (MIPAS) aboard the Environmental Satellite (Envisat) (Fischer et al., 2008; Griessbach et al., 2015). The spatial sampling of MIPAS in the nominal operation mode during the years 2005 to 2012 was $410 \mathrm{~km}$ (horizontal) $\times 1.5 \mathrm{~km}$ (vertical) at 6 to $21 \mathrm{~km}$ altitude (Raspollini et al., 2013). MIPAS has lower spatial resolution than CALIOP, but it is more sensitive to low aerosol concentrations due to the limb observation geometry.

We also consider the work of Theys et al. (2013) and Clarisse et al. (2014) for further validation of the reconstructed emissions as well as the forward simulation results. Satellite observations such as the second Global Ozone Monitoring Experiment (GOME-2) and the Infrared Atmospheric Sounding Interferometer (IASI) data sets were used in case studies, including the volcanic eruption of the Nabro in 2011. GOME-2, a UV-visible spectrometer covering the 240-790 nm wavelength interval with a spectral resolution of $0.2-0.5 \mathrm{~nm}$ (Munro et al., 2006), measures the solar radiation backscattered by the atmosphere and reflected from the surface of the Earth in a nadir viewing geometry. The instrument is in a sun-synchronous polar orbit on board the Meteorological Operational satellite-A (MetOp-A). It has an Equator-

\footnotetext{
${ }^{1}$ Browse images from http://oiswww.eumetsat.org/IPPS/html/ MTP (last access: 10 July 2015).

${ }^{2}$ Browse images at http://www-calipso.larc.nasa.gov/products/ lidar/browse_images/production (last access: 10 July 2015).
}

crossing time of 09:30 LT (local time) on the descending node. The ground spatial resolution is about $80 \mathrm{~km} \times 40 \mathrm{~km}$ and the full width of a GOME-2 scanning swath is $1920 \mathrm{~km}$, which allows for nearly daily global coverage. IASI was launched in 2006 on board MetOp-A (Clerbaux et al., 2009; Hilton et al., 2012). Global nadir measurements are obtained twice a day (at 09:30 and 21:30 mean local equatorial time). Its footprint ranges from a small to medium size, a $12 \mathrm{~km}$ diameter circle at nadir and an ellipse with 20 and $39 \mathrm{~km}$ axes at the scan extremes. Measurements of many trace gases including $\mathrm{SO}_{2}$ are available from the IASI instrument (Clarisse et al., 2011).

\section{Inverse modeling and simulation system}

\subsection{Inversion by means of sequential importance resampling}

A flow chart of the inverse modeling and simulation system proposed in this paper is shown in Fig. 1. Important system inputs consist of a specification of the time- and altitudedependent domain for $\mathrm{SO}_{2}$ emissions, the total number of air parcels for the final forward simulation, the satellite data, and the meteorological data. The Lagrangian transport model MPTRAC is used to perform unit simulations in a parallel manner. In this study, an inversion approach based on the concept of sequential importance sampling (Gordon et al., 1993) in combination with different resampling strategies is proposed to iteratively estimate the relative distribution of the volcanic $\mathrm{SO}_{2}$ emissions. Sequential importance resampling is a special type of particle filter (Del Moral, 1996) that is used to estimate the posterior density of state variables given indirect observations. The method approximates the probability density by a weighted set of samples. Here we infer the probability density of "hidden" variables (i.e., the $\mathrm{SO}_{2}$ emissions at the volcano) based on indirect observations (AIRS detections of the $\mathrm{SO}_{2}$ plume). The method provides the relative distribution of the $\mathrm{SO}_{2}$ emissions. The $\mathrm{SO}_{2}$ emission rates can then be calculated by assuming that the total $\mathrm{SO}_{2}$ mass is known a priori. Together with the final forward simulation results, the emission rates are the main output of the system.

We assume that the volcanic $\mathrm{SO}_{2}$ emissions occur in a time- and altitude-dependent domain $E:=\left[t_{0}, t_{\mathrm{f}}\right] \times \Omega$. Here $t_{0}$ and $t_{\mathrm{f}}$ denote the initial and final time of possible emissions, and $\Omega:=\left[\lambda_{\mathrm{c}}-0.5 \Delta_{\lambda}, \lambda_{\mathrm{c}}+0.5 \Delta_{\lambda}\right] \times\left[\phi_{\mathrm{c}}-0.5 \Delta_{\phi}, \phi_{\mathrm{c}}+\right.$ $\left.0.5 \Delta_{\phi}\right] \times\left[h_{1}, h_{\mathrm{u}}\right]$ corresponds to a rectangular column oriented vertically and centered over the volcano. The horizontal coordinates for the volcano are defined by geographic longitude $\lambda_{\mathrm{c}}$ and geographic latitude $\phi_{\mathrm{c}}$. Note that $\Delta_{\lambda}$ and $\Delta_{\phi}$ can be varied to control the area of the horizontal crosssection of the column for a particular simulation. $h_{1}$ and $h_{\mathrm{u}}$ represent the lower and upper boundary of the altitude range used to constrain the emissions. We discretize the domain $E$ 


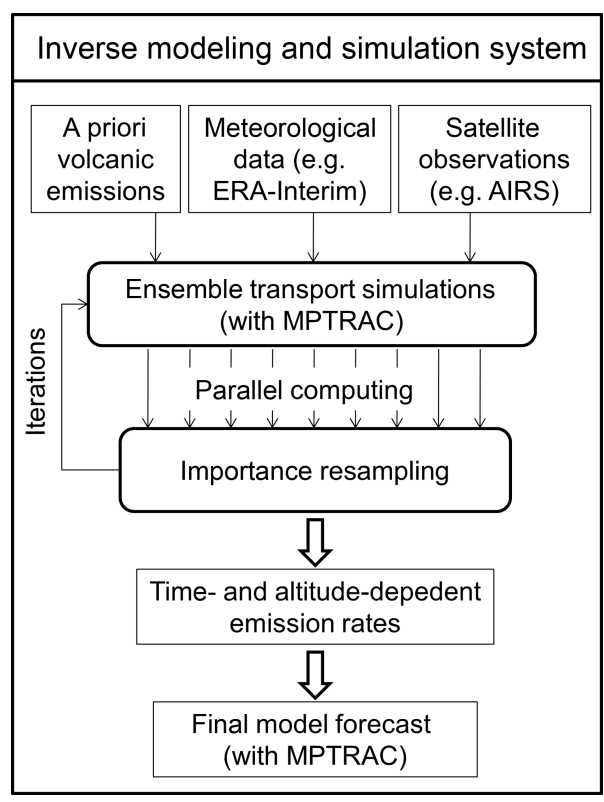

Figure 1. Flow chart of the proposed inverse modeling and simulation system to infer volcanic $\mathrm{SO}_{2}$ emissions rates and to perform transport simulations.

along the time axis and the altitude axis with $n_{t}$ and $n_{h}$ uniform intervals, respectively. This leads to $N=n_{t} \cdot n_{h}$ disjoint subdomains, for which we perform $N$ parallel "unit simulations", correspondingly. Each unit simulation is conducted with an initialization of a given number of air parcels emitted in only one of the disjoint subdomains of $E$.

The $N$ unit simulations at each iteration can be considered as a weighted set of particles, $\left\{\left(w_{i j}, s_{i j}\right), i=1, \ldots, n_{t}, j=\right.$ $\left.1, \ldots, n_{h}\right\}$, with $s_{i j}$ and $w_{i j}$ representing the hidden initialization and the relative posterior probabilities of the occurrence of the air parcels for the $(i, j)$ th-unit simulation, respectively. The importance weights $w_{i j}$ have to satisfy the normalization condition $\sum_{i=1}^{n_{t}} \sum_{j=1}^{n_{h}} w_{i j}=1$. By rearranging the importance weights in matrix form, we obtain $\mathbf{W}=$ $\left(w_{i j}\right)_{i=1, \ldots, n_{t} ; j=1, \ldots, n_{h}}$ and use this notation in the subsequent sections. This way, the task of reconstructing the altituderesolved time series of the volcanic emissions from satellite observations mathematically turns into the task of iteratively estimating the importance weight matrix $\mathbf{W}$. In order to find more realistic importance weights that reflect the relative distribution of emissions in the subdomains, unit simulations then have to be performed to estimate importance weights in an iterative scheme. Changes in the importance weights indicate how many air parcels should be reassigned to each subdomain and considered as new initial conditions for the next iteration. In our case, after 1-2 iterations we can already obtain rather stable importance weights that lead to good simulation results. Nevertheless, in order to establish a robust computational procedure, we defined a stopping criterion for the iterative update process (see Sect. 3.3 for details). Based on the importance weights obtained in the final iteration, the total number of $\mathrm{SO}_{2}$ air parcels is redistributed in the entire initialization domain. With the reconstructed emission time series, the final forward simulations are performed.

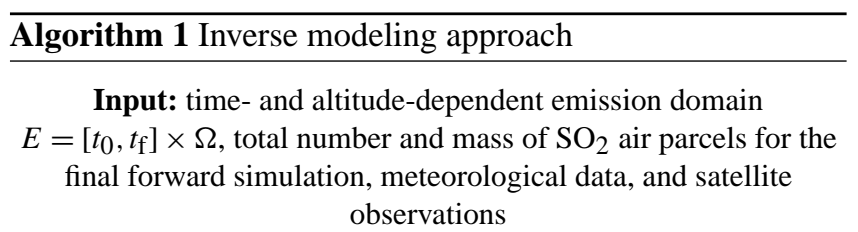

1. Discretize the entire domain $E$, by considering $n_{t}$ equal-sized intervals on the time axis and $n_{h}$ heights along the altitude axis, respectively.

2. Distribute air parcels in all $N=n_{t} \cdot n_{h}$ subdomains of $E$ uniformly. Set initial weights according to the equal-probability strategy, $w_{i j}=1 / N$.

3. Do

4. Perform $N$ unit simulations in parallel and calculate CSI time series.

5. Update importance weights $w_{i j}$ based on one of the weightupdating schemes described in Sect. 3.3. Resample air parcels distributions according to importance weights.

6. While relative difference between adjacent importance weight matrices according to Eq. (7) is larger than a given tolerance.

7. Distribute air parcels in the entire initialization domain based on final importance weights.

8. Perform final forward simulation based on the reconstructed altitude-dependent time series of emissions.

Output: horizontal and vertical trace gas distributions (column densities, lists of air parcels) and diagnostic data (CSI, FAR and POD plots) at different model time steps

Our inverse modeling approach is summarized in Algorithm 1 . We first discretize the time- and altitude-dependent domain for $\mathrm{SO}_{2}$ emissions and initialize air parcels in all subdomains with equal probability, i.e., distribute them in time and space uniformly (steps 1-2). Then, as the core part of the system, an iterative procedure (steps 3-6) is used to update the importance weights by performing unit simulations and applying different weight-updating schemes (see details below). The iterative procedure ends when a given termination criterion (step 6) is satisfied. Finally, we use the calculated importance weights to resample the $\mathrm{SO}_{2}$ air parcels in all subdomains and summarize the information in the entire initialization domain (step 7). With the reconstructed initializations, the final forward simulations are performed (step 8).

\subsection{A measure of goodness-of-fit for forward simulations}

To evaluate the goodness-of-fit of the forward simulations and to estimate the importance weights $w_{i j}$, we use the CSI (Schaefer, 1990), adapting the approach presented by Hoffmann et al. (2016). The CSI is a frequently used measure 
to validate simulations of volcanic eruption events (Stunder et al., 2007; Webley et al., 2009; Harvey et al., 2016). The CSI measures the agreement between the model forecasts and the satellite observations by comparing the spatial extent of the modeled and observed $\mathrm{SO}_{2}$ plumes over time. Model and observation data are analyzed on a $1^{\circ} \times 1^{\circ}$ longitudelatitude grid, accumulated over $12 \mathrm{~h}$ time periods. At midand low latitudes there are typically two satellite overpasses per day (at 01:30 and 13:30 LT). An accumulation time interval shorter than $12 \mathrm{~h}$ may lead to time periods in the CSI analysis during which the satellite observations do not cover the volcanic plume at all. Therefore, $12 \mathrm{~h}$ is a reasonable minimum time period for this analysis. A model forecast is classified as "positive" if the $\mathrm{SO}_{2}$ amount in a grid box exceeds a certain threshold (for instance, $0.1 \%$ of the assumed total $\mathrm{SO}_{2}$ mass of all parcels in this case). Likewise, a satellite observation is classified as positive if the mean SI of the AIRS footprints within a grid box exceeds a given threshold. Here we use $2 \mathrm{~K}$, which approximately corresponds to $4 \mathrm{DU}$ (Dobson Units; $1 \mathrm{DU}=2.85 \times 10^{-5} \mathrm{~kg} \mathrm{~m}^{-2}$ ) in terms of $\mathrm{SO}_{2}$ column density (Hoffmann et al., 2014).

The CSI is calculated based on event counts of positive and negative model forecasts and satellite observations, respectively. To calculate the CSI, a $2 \times 2$ contingency table of the event counts is created first. By denoting the number of positive forecasts with positive observations as $c_{x}$, the number of negative forecasts with positive observations as $c_{y}$, and the number of positive forecasts with negative observations as $c_{z}$, the CSI is defined as

$\mathrm{CSI}=c_{x} /\left(c_{x}+c_{y}+c_{z}\right)$.

The CSI provides the ratio of successful forecasts $\left(c_{x}\right)$ to the total number of forecasts that were actually made $\left(c_{x}+c_{z}\right)$ or should have been $\left(c_{y}\right)$. Note that the fourth element of the $2 \times 2$ contingency table, the number $c_{w}$ of negative forecasts with negative observations, is not considered in the definition of the CSI. Although $c_{w}$ is neglected to simply avoid cases of no interest, it should be noted that this causes the CSI to be a biased indicator of forecast skills (Schaefer, 1990). Alternative ways to evaluate the forward simulations, such as the false alarm rate (FAR), namely, the ratio of wrong predictions to the total number of forecasts,

$\mathrm{FAR}=c_{z} /\left(c_{x}+c_{z}\right)$

and the probability of detection (POD), denoting the ratio of observations that are correctly forecasted to the total number of observations,

$\mathrm{POD}=c_{x} /\left(c_{x}+c_{y}\right)$

can also provide relevant information in addition to the CSI.
Since we compare simulation results with satellite observations on a discrete-time finite horizon ( $12 \mathrm{~h}$ time intervals), for each unit simulation the CSI values obtained at different times $t_{k}$ can be summarized as a data vector of length $n_{k}$. We denote the data vector for the $(i, j)$ th-unit simulation as $\left(\mathrm{CSI}_{k}^{i j}\right)$ with $k=1, \ldots, n_{k}$ for later use in subsequent sections.

\subsection{Iterative update of importance weights and resampling strategies}

A straightforward scheme for updating the importance weights $w_{i j}$ is given by

$w_{i j}=m_{i j} / \sum_{a=1}^{n_{t}} \sum_{b=1}^{n_{h}} m_{a b}$,

where the measure $m_{i j}$ is defined as

$m_{i j}=\left(\sum_{k=1}^{n_{k}} \operatorname{CSI}_{k}^{i j}\right) / n_{k}$.

Here, $n_{k}$ denotes the total number of the time instants of satellite data ( $12 \mathrm{~h}$ intervals) that are used for computing the CSI values. This measure considers an equal weighting of the obtained CSI values of the time series data. As will be shown in Sect. 4, the weight-updating scheme defined by Eqs. (4) and (5), referred to as "mean rule" below, leads to simulations that can capture the basic transport dynamics for the Nabro case study pretty well. However, by definition any non-zero CSI value over the entire observation time period will result in a non-zero importance weight and hence it cannot fully exclude cases in which emissions are actually not likely to occur at all. A few representative examples concerning this issue will be shown in Sect. 4.2.

In practice, new $\mathrm{SO}_{2}$ emissions and already present $\mathrm{SO}_{2}$ emissions from earlier times are often hard to be distinguished in an initial time period, but they are often more clearly separated at later times. Therefore, an improved measure is suggested here as

$m_{i j}=\frac{\sum_{k=1}^{n_{k}^{\prime}} \operatorname{CSI}_{k}^{i j}}{n_{k}^{\prime}} \cdot \frac{\sum_{k=n_{k}^{\prime}+1}^{n_{k}} \operatorname{CSI}_{k}^{i j}}{n_{k}-n_{k}^{\prime}}, 1 \leq n_{k}^{\prime}<n_{k}$,

where $n_{k}^{\prime}$ is considered as a "split point" for the CSI time series. As will be demonstrated in Sect. 4, the weight-updating scheme defined by Eqs. (4) and (6), referred to as "product rule", can capture not only the basic but also the fine details of the $\mathrm{SO}_{2}$ transport for the Nabro case study. This is achieved by putting a stronger "and" constraint on the first and second period of the CSI time series. Successful model forecasts in only one of the two time periods will not lead to high importance weights. This way, unlikely local emission patterns can be detected better and excluded, leading to more 
accurate simulations both globally and locally. Note that the length of the initial time period might be different for each particular volcanic eruption. The split point is chosen at $48 \mathrm{~h}$ for the simulations presented here. Nevertheless, the general setting of Eq. (6) allows one to control the trade-off between both time periods by tuning $n_{k}^{\prime}$ accordingly.

In each iteration of the inversion procedure the measures and corresponding weight-updating schemes based on the CSI data vectors of all unit simulations are evaluated. Furthermore, the numbers of $\mathrm{SO}_{2}$ air parcels in all subdomains (i.e., the discretized grid boxes of the initialization domain along the time axis and the altitude axis) are scaled linearly with the corresponding importance weights. This resampling step redistributes the total $\mathrm{SO}_{2}$ mass of all air parcels between the subdomains, according to the current importance weights. The iterative procedure ends when the change of importance weight matrices of successive iterations becomes sufficiently small. To quantify the change we use the relative difference $d$ calculated as

$d\left(\mathbf{W}^{l+1}, \mathbf{W}^{l}\right)=\frac{\left\|\mathbf{W}^{l+1}-\mathbf{W}^{l}\right\|_{\mathrm{F}}}{\max \left(\left\|\mathbf{W}^{l+1}\right\|_{\mathrm{F}},\left\|\mathbf{W}^{l}\right\|_{\mathrm{F}}\right)}, l \geq 1$,

where $l$ denotes the iteration number and $\|\cdot\|_{F}$ corresponds to the Frobenius norm,

$$
\left\|\mathbf{W}^{l}\right\|_{\mathrm{F}}=\sqrt{\sum_{i=1}^{n_{t}} \sum_{j=1}^{n_{h}}\left|w_{i j}^{l}\right|^{2}} .
$$

We selected a threshold of $1 \%$ for the relative difference $d$ in our simulations. In the Nabro case study the final importance weights were obtained after three iterations.

\section{Nabro case study}

\subsection{Simulation setup}

The Nabro is a stratovolcano located at $\left(13^{\circ} 22^{\prime} \mathrm{N}, 41^{\circ} 42^{\prime} \mathrm{E}\right)$ in Eritrea, Africa. There were no historical eruptions recorded before June 2011. However, at about 20:30 UTC on 12 June 2011, a series of earthquakes resulted in a strong volcanic eruption. Volcanic activity lasted over 5 days and various plume altitudes occurred. Clarisse et al. (2012) reported a total $\mathrm{SO}_{2}$ mass of approximately $1.5 \times 10^{9} \mathrm{~kg}$ in the UT/LS region based on measurements by the IASI. As a significant amount of ash was emitted, some regional flights had to be canceled. ${ }^{3}$ Due to the complexities of its emission patterns and transport processes related to the Asian monsoon circulation, we consider the Nabro eruption as an excellent example to validate our inverse modeling approach.

As described in Sect. 3, we here consider different types of simulations, i.e., unit simulations used for the reconstruction

\footnotetext{
${ }^{3}$ See http://www.bbc.com/news/world-africa-13778171 (last access: 22 June 2015).
}

of the altitude-dependent time series of the Nabro $\mathrm{SO}_{2}$ emissions and final forward simulations based on the estimated emission data. Regarding the unit simulations we assume that the $\mathrm{SO}_{2}$ emissions occurred in the vicinity of the Nabro volcano within a horizontal area of $1^{\circ} \times 1^{\circ}$ at 0 to $30 \mathrm{~km}$ altitude between 12 June 2011, 12:00 UTC and 18 June 2011, 00:00 UTC. During this time period, AIRS detected volcanic $\mathrm{SO}_{2}$ in nearly 75000 satellite footprints. Hence, the inversion of $\mathrm{SO}_{2}$ emissions is constrained by a large number of satellite observations. For the numerical discretization of the emission domain, a time step of $1 \mathrm{~h}$ and an altitude step of $250 \mathrm{~m}$ are applied. This discretization leads to $132 \times 120=15840$ subdomains. For the reconstruction of the $\mathrm{SO}_{2}$ emission rates we use the AIRS satellite data between 13 June 2011, 00:00 UTC and 23 June 2011 00:00 UTC, which are measured at nearly fixed local times of 01:30 and 13:30. In each iteration of the inversion procedure, 15840 unit simulations for the subdomains were carried out. These large-scale simulations were performed in parallel on the Jülich Research on Petaflop Architectures (JuRoPA) supercomputer ${ }^{4}$.

For the final forward simulations, starting on 12 June 2011, 12:00 UTC and running for 15 days, a total number of 2 million air parcels are considered. The sum of these parcels then hold the total Nabro emission mass, which is estimated as $1.5 \times 10^{9} \mathrm{~kg}$ according to the work of Clarisse et al. (2012). AIRS satellite data between 13 June 2011, 00:00 UTC and 28 June 2011, 00:00 UTC are considered to validate these simulation results. In Sect. 4.6 we compare final forward simulations obtained with different weight-updating schemes. The first scheme assumes that the $\mathrm{SO}_{2}$ emissions have equal probability of occurrence in the initialization domain. Namely, equal importance weights, $w_{i j}=1 / 15840$, are considered for initializations in all 15840 subdomains, which leads to constant and vertically uniform emission rates for the simulation. This type of simulation does not require any measurement information such as the satellite observations. Although such an assumption is unrealistic in practice, it serves as a good initial condition for our inversion procedure to estimate the final importance weights with the other weightupdating schemes. By applying the mean rule and the product rule, the iterative inversion procedure reconstructs more realistic time- and altitude-dependent volcanic $\mathrm{SO}_{2}$ emission rates than the equal-probability scheme.

\subsection{Examples of unit simulations}

In order to illustrate the basic idea behind the weightupdating schemes in the frame of the proposed inversion approach, we first study individual unit simulations. Figures 2 to 4 show the results of the CSI analysis for three representative examples. Since the AIRS satellite data used here lack vertical information, only horizontally projected simulation

\footnotetext{
${ }^{4}$ See http://www.fz-juelich.de/ias/jsc/juropa (last access: 22 June 2015)
} 

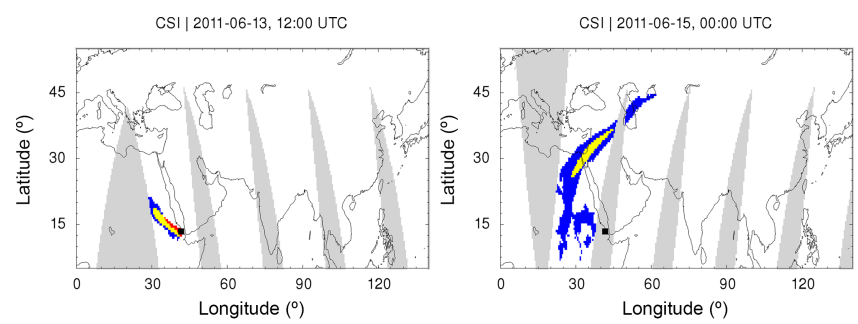

CSI | 2011-06-17, 12:00 UTC
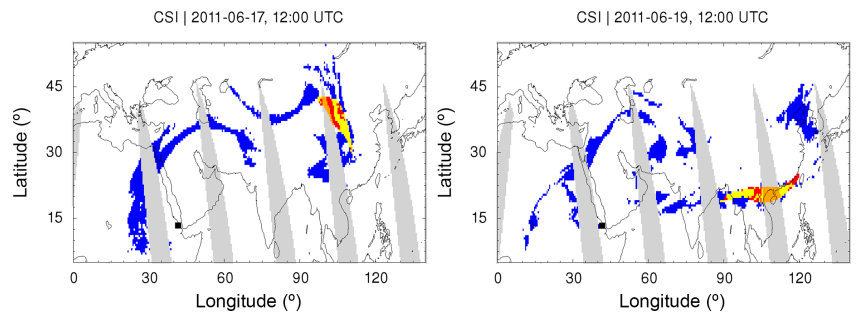

Figure 2. Unit simulation for the Nabro case study with air parcels initialized around 13 June, 00:00 UTC and $16.5 \mathrm{~km}$ altitude. The CSI analysis is performed on a $1^{\circ} \times 1^{\circ}$ longitude-latitude grid. Gray color indicates missing satellite data. Orange color corresponds to positive model forecasts, but lack of satellite data. Yellow color indicates positive forecasts and positive satellite observations. Blue color corresponds to negative forecasts with positive observations. Red color corresponds to positive forecasts with negative observations. The black square shows the location of the Nabro volcano.

results are used to test the data match in grid boxes. $\mathrm{SO}_{2}$ column densities are not compared directly. As mentioned earlier, the analysis is performed on a $1^{\circ} \times 1^{\circ}$ longitude-latitude grid.

Based on these examples, the unit simulations can be classified into three categories. In the first category, we consider the cases in which the assigned initialization in the specific subdomain yields $\mathrm{SO}_{2}$ air parcel trajectories that match the satellite observations well. As an example, Fig. 2 shows the unit simulation with an initialization of emissions on 13 June 2011, 00:00 UTC $\pm 30 \mathrm{~min}$ and at $(16.5 \pm 0.125) \mathrm{km}$ altitude. This simulation shows excellent agreement with parts of the satellite observations over the entire simulation time period. This indicates that $\mathrm{SO}_{2}$ emissions most likely occurred in the corresponding temporal and spatial subdomain.

In the second category, we consider the cases where model forecasts quickly mismatch the satellite observations. As an example, Fig. 3 shows a model forecast related to emissions released at the same time as in the first example, but at $(29 \pm 0.125) \mathrm{km}$ altitude. Figure 3 illustrates that the forecasts agree with the satellite observations only shortly after the volcanic eruption. After $12 \mathrm{~h}$ the $\mathrm{SO}_{2}$ air parcels were already transported westwards, not agreeing with the satellite observations. Hence, this indicates that $\mathrm{SO}_{2}$ emissions were not likely to occur in this temporal and spatial subdomain.
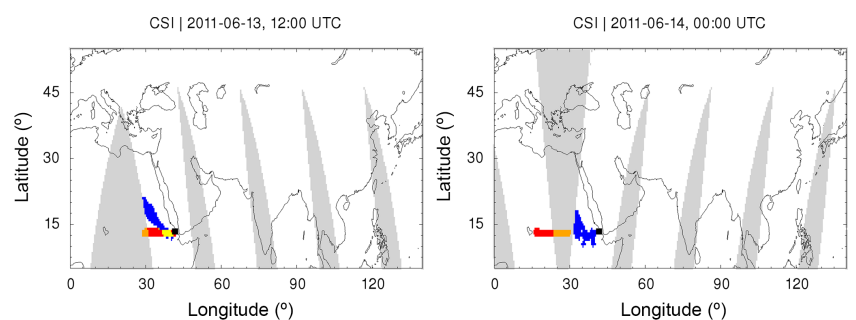

CSI | 2011-06-14, 12:00 UTC
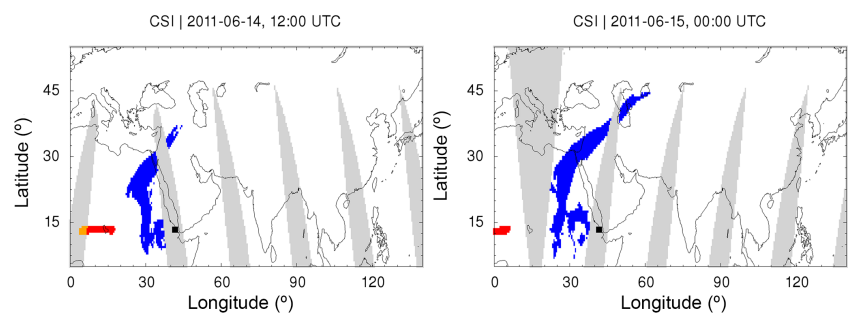

Figure 3. Same as Fig. 2, but for a unit simulation initialized at $29 \mathrm{~km}$ altitude. This simulation almost immediately disagrees with the satellite observations. Note that the time steps are partly different from those shown in Fig. 2.
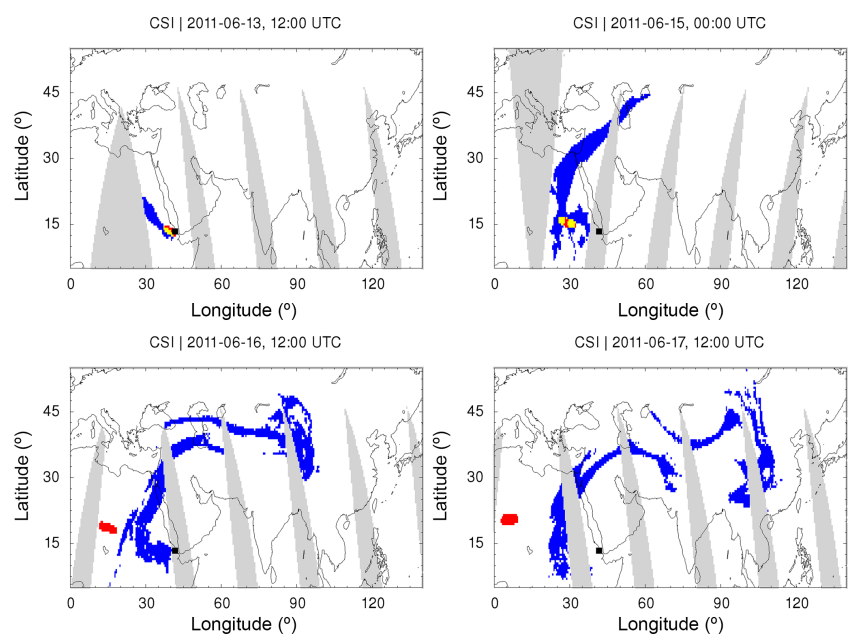

Figure 4. Same as Fig. 2, but for a unit simulation initialized at $20 \mathrm{~km}$ altitude. This simulation agrees with the satellite observations for about $48 \mathrm{~h}$, but disagrees at later times. Note that the time steps are partly different from those shown in Figs. 2 and 3.

In the third category, successful model forecasts can be found for a longer time period compared with second category. The example presented in Fig. 4, with air parcels released at the same time but at $(20 \pm 0.125) \mathrm{km}$ altitude, shows agreement between the model forecast and the satellite observations for about 2 days. However, the $\mathrm{SO}_{2}$ air parcels were transported westwards and are not agreeing with the satellite observations at later times. Also in this temporal and spatial subdomain $\mathrm{SO}_{2}$ emissions were not likely to occur.

In summary, our inversion approach is supposed to be able to identify and separate all cases in the aforementioned three different categories and yield suitable importance weights. 
As will be shown in the subsequent sections, both the mean rule and the product rule work well for the cases in the first category. They can therefore capture the basic transport dynamics. However, for less realistic situations in the second and third category the application of the mean rule still yields small importance weights. The product rule can be used to exclude these unrealistic cases and yield proper importance weights by choosing a suitable split point of the obtained CSI time series. As will be shown in Sect. 4.6, it is therefore considered as a superior strategy, both qualitatively and quantitatively.

\subsection{Reconstruction of volcanic $\mathrm{SO}_{2}$ emissions}

Suitable initializations are necessary in order to perform reliable final forward simulations. For this purpose we estimate the time- and altitude-dependent volcanic $\mathrm{SO}_{2}$ emissions with the iterative inversion approach outlined in Sect. 3. The time- and altitude-resolved emission rates are estimated based on the different weight-updating schemes. By assuming a total mass of $1.5 \times 10^{9} \mathrm{~kg}$ for the entire initialization domain, the equal-probability resampling strategy (first guess) considers an equal weight of $w_{i j}=1 / 15840$ that leads to constant and vertically uniform emission rates of approximately $0.1052 \mathrm{~kg} \mathrm{~m}^{-1} \mathrm{~s}^{-1}$. However, note that such an assumption is in general not very realistic, even by posing further time- and altitude-constraints, because volcanic eruptions often change over time significantly and emissions are also not uniformly distributed with altitude.

Figure 5 shows the temporally and spatially resolved $\mathrm{SO}_{2}$ emission rates reconstructed by applying the mean rule and the product rule, respectively. The application of the mean rule results in temporally and spatially broader areas with smaller emission rates (Fig. 5, top) up to about $1.5 \mathrm{~kg} \mathrm{~m}^{-1} \mathrm{~s}^{-1}$. As shown in the figure, some unlikely cases of local emissions mentioned in Sect. 4.2 are not excluded. In contrast, the application of the product rule emphasizes the more likely cases and excludes unlikely cases (Fig. 5, bottom). Its maximum emission rate is about 6 times larger than that of the mean rule. In particular, the peak emission rates on 13 June 2011, 00:00 UTC, 14 June 2011, 15:00 UTC, and 16 June 2011, 10:00 UTC are approximately 9.28, 0.57, and $0.70 \mathrm{~kg} \mathrm{~m}^{-1} \mathrm{~s}^{-1}$, respectively. The corresponding peak emission rates estimated by the mean rule are approximately $1.50,0.56$, and $0.42 \mathrm{~kg} \mathrm{~m}^{-1} \mathrm{~s}^{-1}$. Since the total emission considered in this study $\left(1.5 \times 10^{9} \mathrm{~kg}\right)$ is the same for all emission reconstruction schemes, and the mean rule yields some local emissions for unlikely cases (for instance at altitudes above $20 \mathrm{~km}$ ), the emissions for more likely cases (e.g., on 13 June 2011, 00:00 UTC at $16.5 \mathrm{~km}$ altitude) are underestimated.

Our results qualitatively agree with the emission data reconstructed by the backward-trajectory approach presented by Hoffmann et al. (2016). The maximum emission rates obtained by the backward-trajectory approach are in between
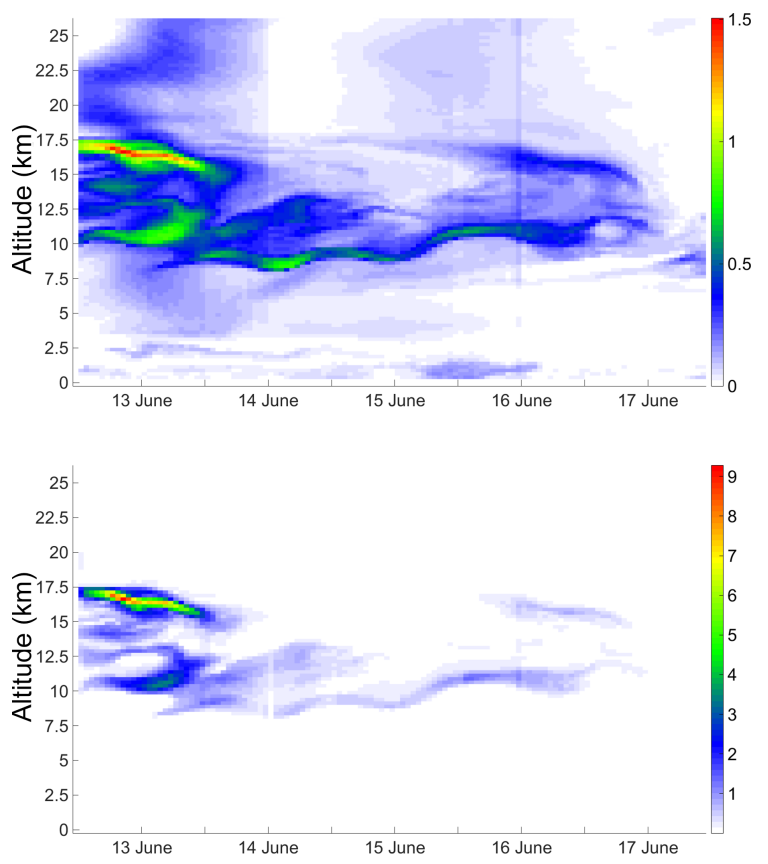

Figure 5. Reconstructed $\mathrm{SO}_{2}$ emission rates $\left(\mathrm{kg} \mathrm{m}^{-1} \mathrm{~s}^{-1}\right)$ for the Nabro eruption in June 2011. Emission rates were obtained by applying the mean rule (top) and the product rule (bottom) weightupdating schemes of the proposed inversion approach (see text for details).

the maximum values obtained with the mean rule and the product rule weight-updating schemes used here. Even closer agreement with the backward-trajectory approach might be achieved by tuning the split point of the product rule accordingly. A sensitivity study for this important tuning parameter will be presented in Sect. 4.4. As shown in Fig. 5, the reconstructed emissions contain very low oscillations, which indicates that the estimations are well constrained by the available AIRS satellite data.

Finally, Fig. 6 shows the reconstructed emission rates integrated over time and altitude. As found earlier, the maximum emission rates for the main eruption on 13 June obtained by the product rule are much higher (up to a factor of 2 for the integrated values) than those obtained by the mean rule. However, this is compensated by lower emission rates by the product rule from 14 to 17 June. Considering the altitude distribution, Fig. 6 (bottom) reveals, especially for the product rule, that most $\mathrm{SO}_{2}$ emissions occurred at 10 to 12 and 15 to $17 \mathrm{~km}$ altitude. We find that the altitude distribution is less constrained for the mean rule than for the product rule.

\subsection{Sensitivity analysis for the weight-updating schemes}

In this section, we first discuss the effect of different choices of the parameter $n_{k}$ for the mean rule weight-updating scheme. As discussed in Sect. 3.2, $n_{k}$ denotes the total num- 

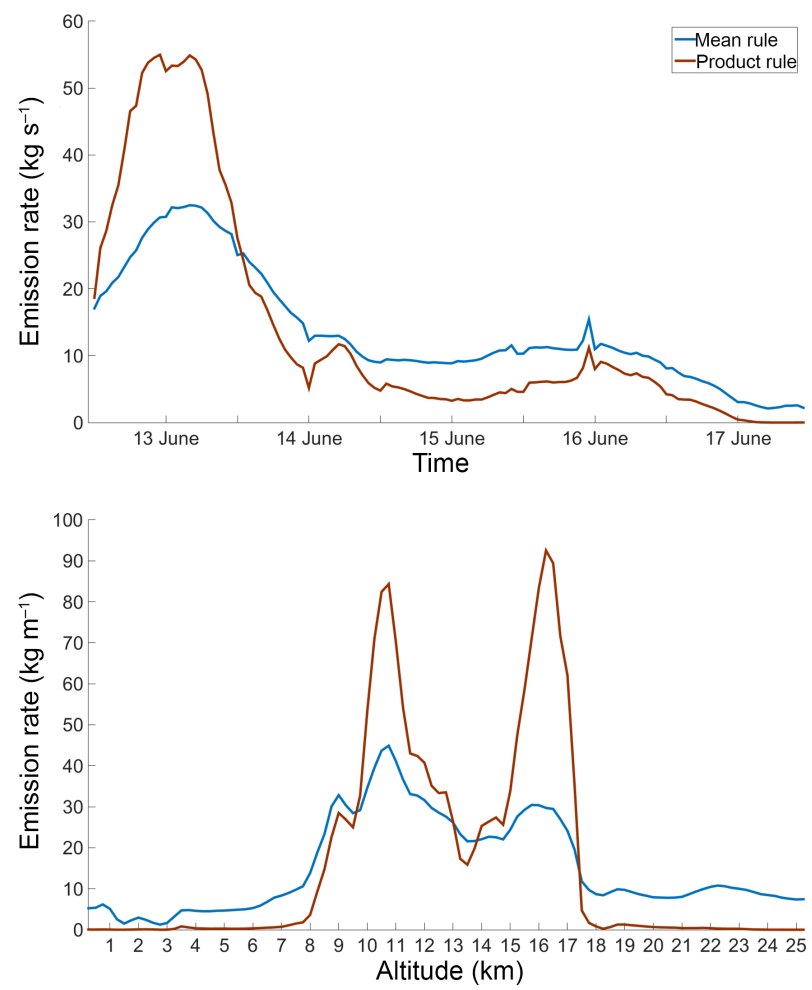

Figure 6. Comparison of reconstructed emission rates integrated over altitude (top) and time (bottom) for the mean rule and the product rule weight-updating schemes.

ber of discrete-time intervals used for the CSI analysis. It directly corresponds to the choice of the final time step of the satellite data. For the reference simulations we have chosen 23 June 2011, 00:00 UTC as the final time, corresponding to $n_{k}=21$. Figure 7 (top) displays a contour plot of the importance weights for the reference case. Figure 7 (middle and bottom) shows the absolute differences with respect to other final times. By choosing 22 June 2011, 00:00 UTC $\left(n_{k}=19\right)$ and 24 June 2011, 00:00 UTC $\left(n_{k}=23\right)$ as the final times, the relative differences of the importance weights are about 9.5 and $10 \%$, respectively. The choice of 22 June 2011 , 12:00 UTC $\left(n_{k}=20\right)$ and 23 June 2011, 12:00 UTC $\left(n_{k}=\right.$ 22 ) as final time lead to smaller relative differences, about 7.2 and $6.2 \%$, respectively (not shown). Based on a visual inspection, the aforementioned different importance weights all show rather similar results in the final forward simulations.

For the product rule, we performed a sensitivity analysis with $n_{k}$ corresponding to the reference date (23 June 2011, 00:00 UTC), but we choose five different split points $n_{k}^{\prime}$, corresponding to $24,36,48,60$, and $72 \mathrm{~h}$ after the beginning of the simulation (13 June 2011, 00:00 UTC). Considering $48 \mathrm{~h}$ as the reference case, the choice of the other split points lead to $23.1,11.3,8.7$, and $13.7 \%$ relative differences of the importance weights. Except in the case of $24 \mathrm{~h}$, which is too short to constrain the time and altitude distribution of the
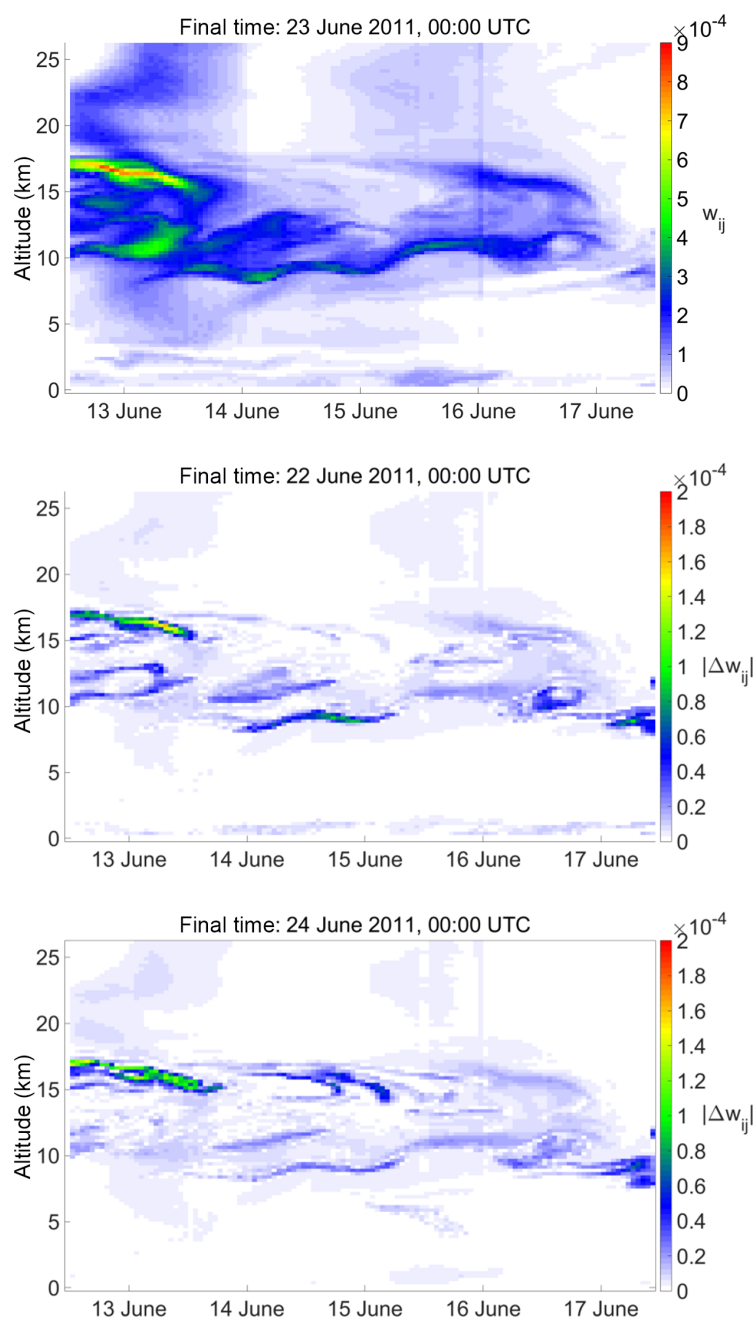

Figure 7. Sensitivity analysis for the mean rule parameter $n_{k}$ : estimated importance weights $w_{i j}$ for choosing 23 June, 00:00 UTC as the final time of used satellite data (top); absolute differences of estimated importance weights $\left|\Delta w_{i j}\right|$ for choosing 23 June, 00:00 UTC as the final time and those for choosing 22 June, 00:00 UTC (middle) and 24 June, 00:00 UTC (bottom) as final time.

$\mathrm{SO}_{2}$ emissions properly, the other three cases lead to weights close to the reference and similar results in the final forward simulations. Figure 8 illustrates the results of this sensitivity test. It shows the importance weights for the reference split point $(48 \mathrm{~h})$ and the absolute differences of the importance weights for split points at 36 and $60 \mathrm{~h}$. Note that the choice of the split point might be different for each particular volcanic eruption. A suitable value for the Nabro case study is $48 \mathrm{~h}$. Nevertheless, our sensitivity analysis shows that the forward simulation results do not vary much with small perturbation $( \pm 12 \mathrm{~h})$ of the chosen split point. 

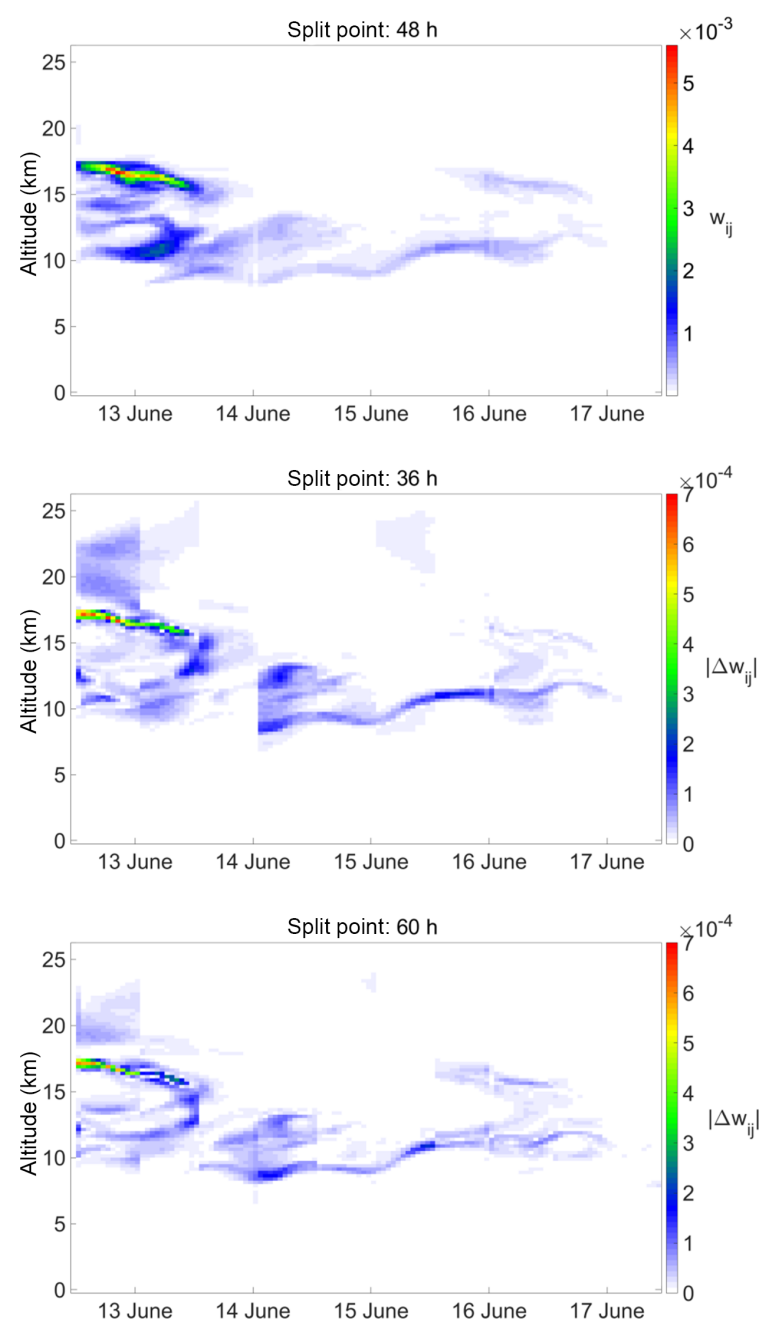

Figure 8. Sensitivity analysis for the product rule parameter $n_{k}^{\prime}$ : estimated importance weights $w_{i j}$ for choosing 23 June 00:00 as the final time of used satellite data and $48 \mathrm{~h}$ as the split point (top); absolute differences of estimated importance weights $\left|\Delta w_{i j}\right|$ for choosing $48 \mathrm{~h}$ as the split point and those for choosing $36 \mathrm{~h}$ (middle) and $60 \mathrm{~h}$ (bottom) as split point.

\subsection{Validation of emission time series}

From MVIRI WV and IR measurements aboard Meteosat-7 (IODC) (Fig. 9, top and bottom panel), we derived time series information (Fig. 9, middle panel) of the eruption history. The WV channel gives information on the high altitude eruption phase because it gets optically thick in the middle troposphere (around $6 \mathrm{~km}$ ), where also the AIRS $\mathrm{SO}_{2}$ channel gets optically thick. In contrast, the IR channel reaches down to the ground and also gives information on low altitude plumes (e.g., on 17 June 2011). The satellite imagery indicates that the strongest eruptions occurred between 13 June 2011, 00:00 and 12:00 UTC. A series of smaller emission events until 16 June 2011, 15:00 UTC were also observed. In particular, there were two short-time peri- ods of strong eruptions on 14 and 16 June 2011. The emission time series derived with our inverse modeling approach are in good temporal agreement with the MVIRI observations.

Injection altitudes of the Nabro eruption have been discussed recently, mostly based on different satellite measurements (Bourassa et al., 2012; Fromm et al., 2013; Vernier et al., 2013; Fromm et al., 2014). For the evaluation of the $\mathrm{SO}_{2}$ heights we used MIPAS and CALIOP $\mathrm{H}_{2} \mathrm{SO}_{4}$ (sulfate aerosol) detections. This aerosol forms from the $\mathrm{SO}_{2}$ and hence, it can be seen as an indicator for the position of the $\mathrm{SO}_{2}$. As other studies already found (Fromm et al., 2014; Clarisse et al., 2014) there was very little ash in the Nabro plume. However, to really make sure that we did not compare with ash, we checked the CALIOP depolarization ratio (no depolarization for liquid particles) and filtered out volcanic ash using the MIPAS volcanic ash detection algorithm (Griessbach et al., 2014). The first CALIOP aerosol observations found the initial plume at $11-15.5 \mathrm{~km}$ over Pakistan and at $15-16.5 \mathrm{~km}$ over Iran on 15 June. Plumes were measured at 18-19 and 8.5-11.5 km over Egypt, at 16-17.5 km over Turkey, at $8.5-11 \mathrm{~km}$ over the Arabian Peninsula, at 16$17 \mathrm{~km}$ over Iran, and at $14-16.2 \mathrm{~km}$ over China on 16 June. MIPAS detected the aerosol resulting from Nabro eruption at $12-16.5 \mathrm{~km}$ over Israel on 14 June. The aerosol layers nearest to the Nabro were measured at $11-16.5 \mathrm{~km}$ on 15 June. They reached $16-18.5 \mathrm{~km}$ on 16 June and $12-15.5 \mathrm{~km}$ on 17 June. The altitudes measured by CALIOP and MIPAS agree within their uncertainties.

The relatively inhomogeneous plume altitudes can also be seen in our reconstructed emission time series, indicating multiple segregated eruption events. The first eruption on 13 June was the strongest and mainly reached altitudes of $15-17 \mathrm{~km}$. This is confirmed by CALIOP and MIPAS measurements that even found aerosol up to $19 \mathrm{~km}$ (in low concentrations). Clarisse et al. (2014) also reported that the early Nabro plume mostly raised to altitudes between 15 and $17 \mathrm{~km}$, which agrees well with our reconstructed emission time series (cf. Fig. 5). On 14 June the second eruption injected the volcanic emissions into altitudes of $9-13 \mathrm{~km}$. At these altitudes aerosols were also measured by CALIOP and MIPAS. Starting from the afternoon of 15 to 16 June, the injection altitude increased again to about $17 \mathrm{~km}$, although emission rates were lower than for the first and second eruption. This is confirmed by MIPAS measurements over Egypt on 17 June reaching up to $17.5 \mathrm{~km}$. Fromm et al. (2013) and Vernier et al. (2013) reported that the initial eruption on 13 June reached altitudes between 15 and $19 \mathrm{~km}$, which is in good agreement with our reconstructed plume. Fromm et al. (2014) reported an injection altitude of $17.4 \mathrm{~km}$ for the third eruption on 16 June, which is less than $1 \mathrm{~km}$ above our reconstructed injection altitude. This initial validation with the different satellite observations indicates that our reconstructed emission time series are reliable. 


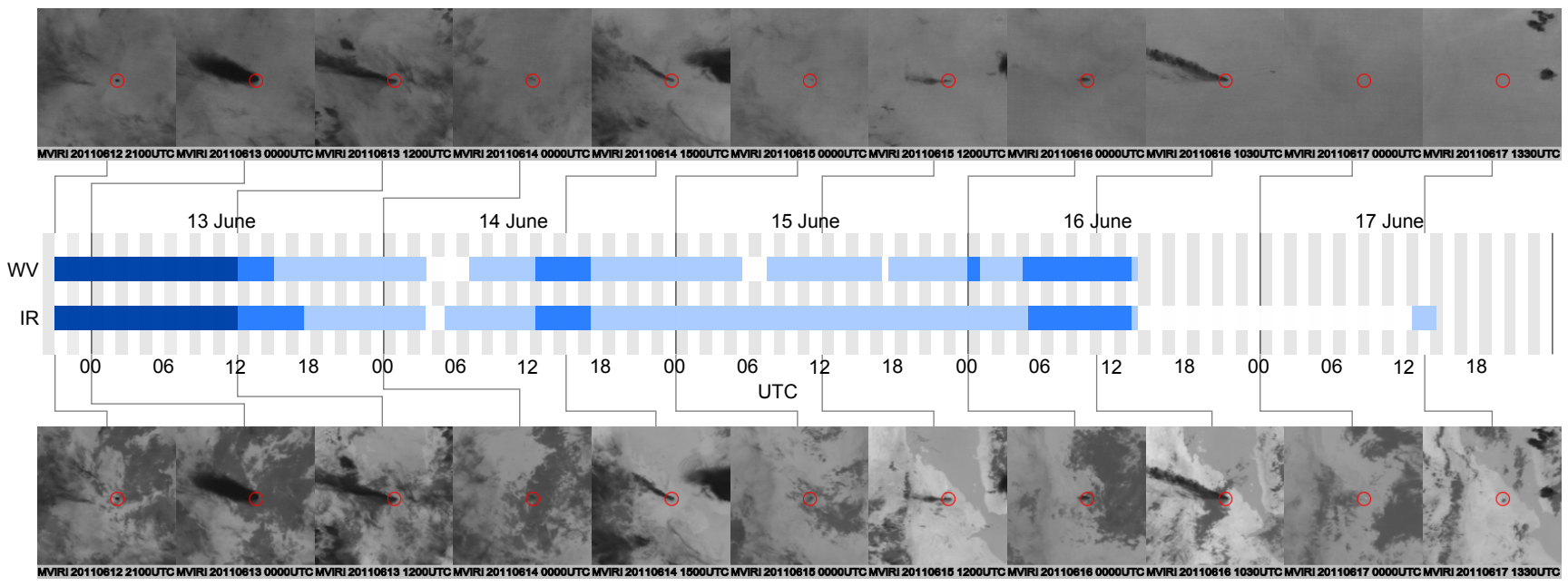

Figure 9. Time line of the 2011 Nabro eruption based on MVIRI IR and WV measurements from Meteosat-7 (IODC). The satellite images were used to roughly estimate the strength of the volcanic activity (white is none, light blue is low level, blue is medium level, dark blue is high level).
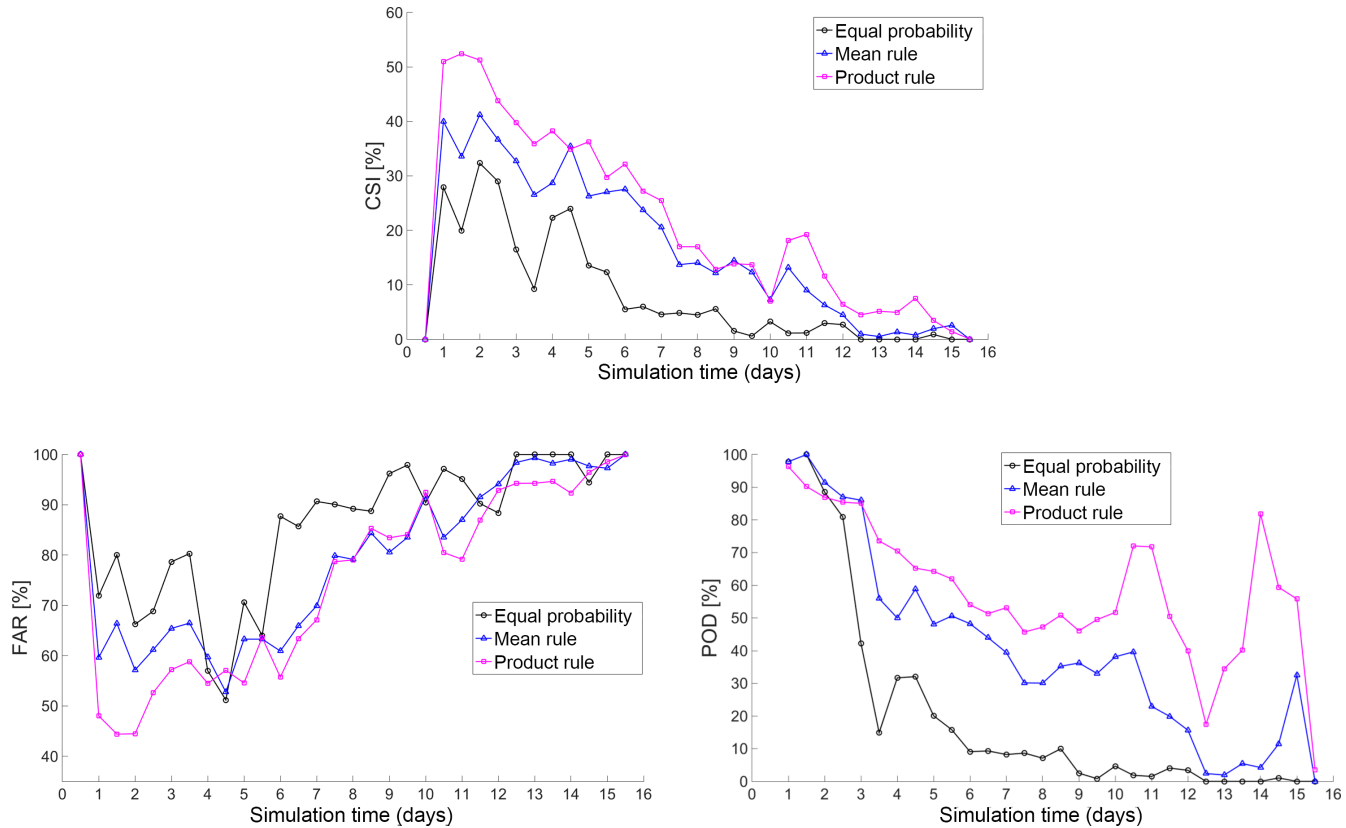

Figure 10. Comparison of the critical success index (CSI), the false alarm rate (FAR), and the probability of detection (POD) time series during $12 \mathrm{~h}$ time intervals obtained by applying the equal-probability strategy, the mean rule, and the product rule.

\subsection{Final forward simulations}

We performed the final forward simulations for the Nabro case study with the initializations obtained in Sect. 4.3. Figure 10 shows the corresponding CSI, POD, and FAR time series based on $12 \mathrm{~h}$ time intervals, obtained by applying the equal-probability strategy, the mean rule, and the product rule, respectively. Note that the equal-probability strategy assumes a constant emission rate in the entire timeand altitude-dependent initialization domain. In all cases, the largest CSI values are found at the beginning of the simulations, followed by an overall decrease towards the end of the simulation. The equal-probability strategy yields a maximum CSI value of $32.3 \%$ and a mean CSI value of $8.1 \%$. The inversions that apply the mean rule and the product rule both lead to higher CSI values. The mean rule yields better simulation results than the equal-probability strategy because it takes into account the temporal variations and inhomogeneous plume altitudes of the volcanic eruption. Its maximum and mean CSI values are 41.2 and $16.6 \%$, respectively. The 

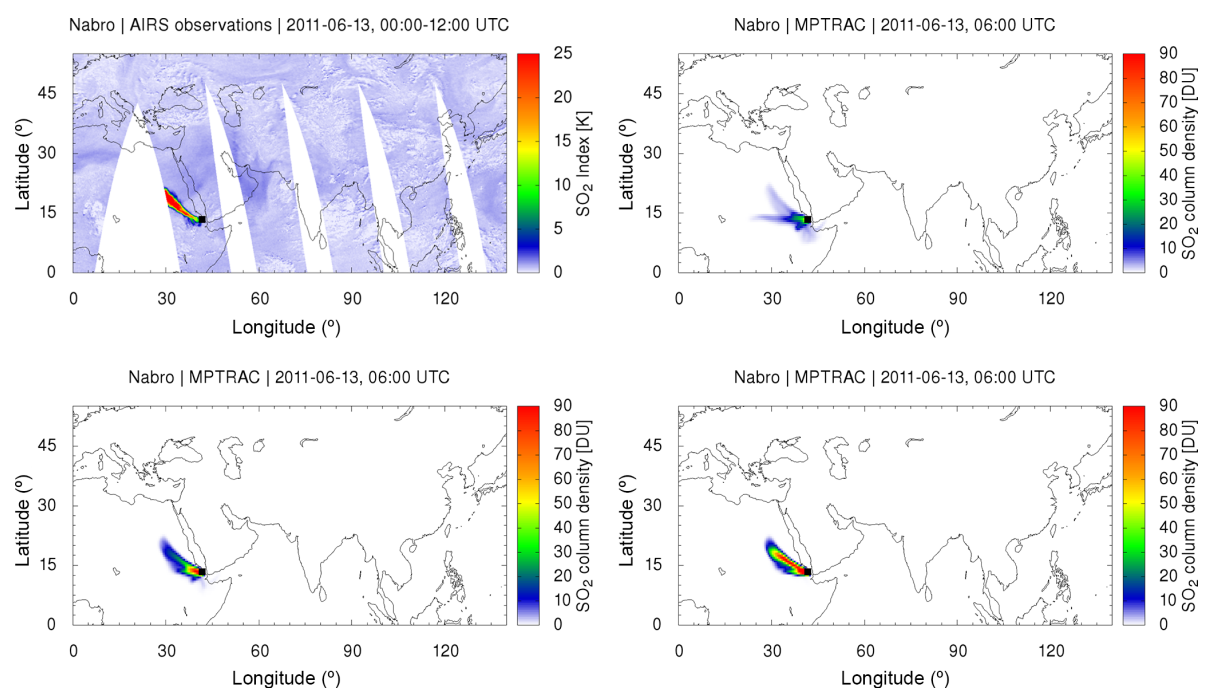

Figure 11. Comparison of AIRS satellite observations (top, left) and MPTRAC simulation results on 13 June 2011, 06:00 UTC based on the equal-probability strategy (top, right), the mean rule (bottom, left), and the product rule (bottom, right).
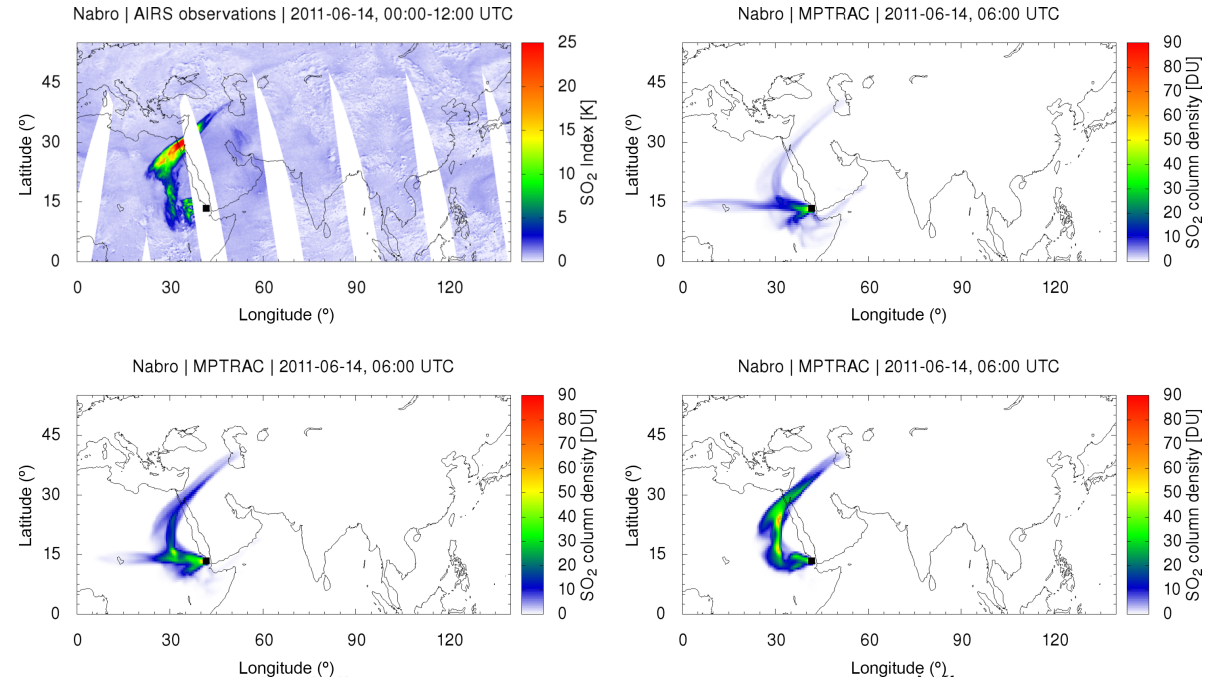

Figure 12. Same as Fig. 11, but for 14 June 2011, 06:00 UTC.

application of the product rule provides the best simulation results of all three cases. Its maximum and mean CSI values are 52.4 and $21.4 \%$, respectively. Our findings for the CSI are confirmed by the FAR and POD time series (Fig. 10, lower panels), which indicates that the use of product rule yields the best simulation results of the three cases.

Figures 11 to 17 compare the simulation results with AIRS satellite observations for selected time steps. $\mathrm{SO}_{2}$ column densities from the model are presented on a $0.5^{\circ} \times 0.5^{\circ}$ longitude-latitude grid. The AIRS $\mathrm{SO}_{2}$ index during corresponding $12 \mathrm{~h}$ time periods is presented on the measurement grid of the instrument. In the case of the equal-probability strategy, unrealistic transport of air parcels westward of the Nabro is found. Accordingly, the estimated $\mathrm{SO}_{2}$ column den- sities for realistic pathways are significantly lower. In the case of the mean rule, more realistic forecasts of the basic $\mathrm{SO}_{2}$ transport patterns are obtained. The simulation results are qualitatively closer to the satellite observations both in time and space. However, unrealistic westward transport of $\mathrm{SO}_{2}$ is still recognizable. The product rule clearly yields the most reliable simulation results of the three cases. It most successfully excludes unlikely local emission patterns.

Our simulation by means of the product rule and AIRS satellite observations yields similar relative horizontal distributions of $\mathrm{SO}_{2}$ on 15 June 2011 compared with IASI satellite data and FLEXPART model output as reported by Theys et al. (2013, Fig. 10a). Simulation results for other days, e.g., for 16, 18 and 20 June 2011, are also similar 

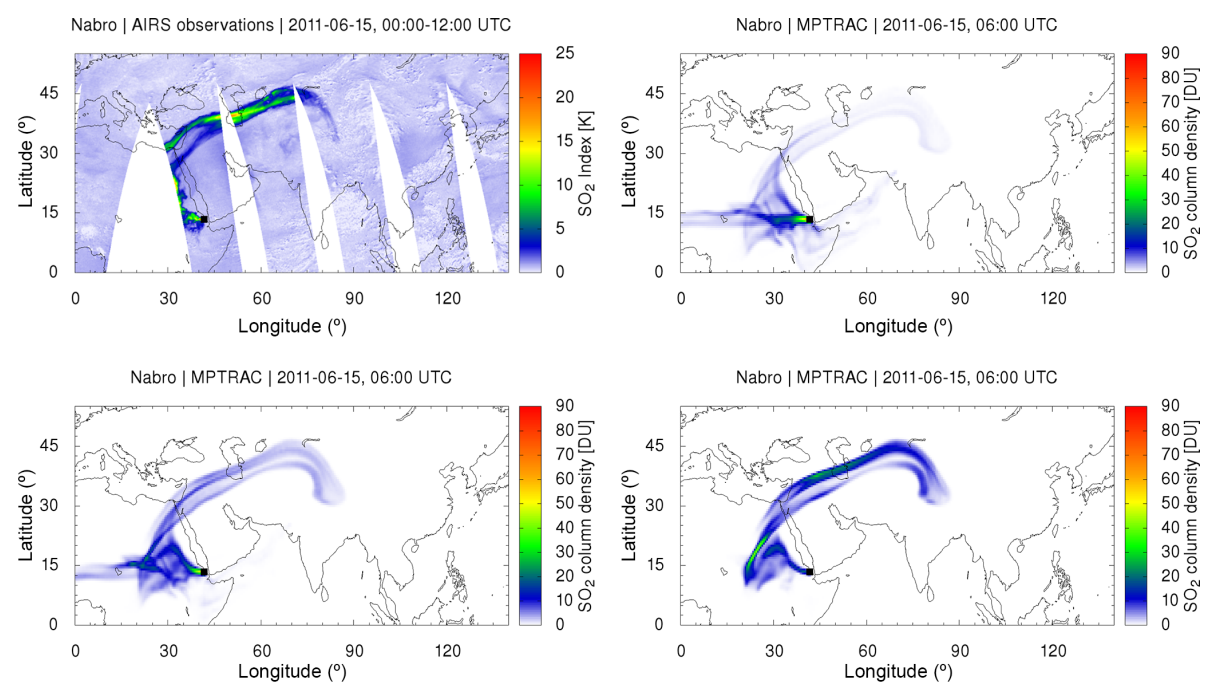

Figure 13. Same as Fig. 11, but for 15 June 2011, 06:00 UTC.
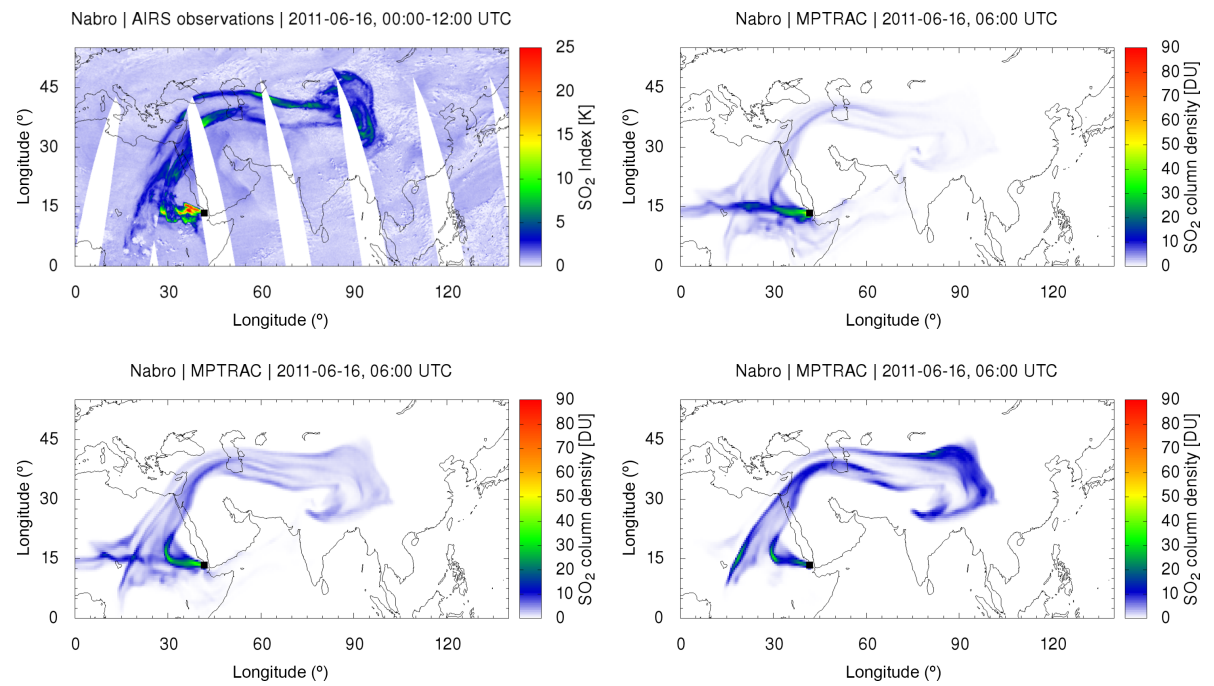

Figure 14. Same as Fig. 11, but for 16 June 2011, 06:00 UTC.

to the GOME-2 satellite retrievals reported by Theys et al. (2013, Fig. 10b-d). Our simulations (Figs. 12 and 14) show more realistic transport patterns on 14 and 16 June 2011 than the FLEXPART model outputs based on the IASI data (Theys et al., 2013, Fig. 12). Besides, the $\mathrm{SO}_{2}$ distributions on 16 and 18 June 2011 in China are not well captured by the FLEXPART model outputs based on the GOME-2 data (Theys et al., 2013, Fig. 10b and c), but by our simulations (Figs. 14 and 15). Furthermore, the $\mathrm{SO}_{2}$ transport patterns of our simulations are in good agreement with IASI observations that were extensively studied in the context of the Nabro eruption (Clarisse et al., 2014, Figs. 6-10).

\section{Conclusions and outlook}

In this paper, we presented an inversion approach based on the concept of sequential importance resampling for the reconstruction of volcanic emission rates from infrared nadir satellite observations. Based on the proposed inversion approach, a new inverse modeling and simulation system, implemented with the Lagrangian transport model MPTRAC, has been developed to enable efficient and reliable transport simulations of volcanic $\mathrm{SO}_{2}$ emissions. Our solution is in general independent of the choice of forward transport model and well suited for massive-parallel supercomputing architectures. The number of air parcels and the total mass of $\mathrm{SO}_{2}$ emission are considered as inputs to the simulation system. Based on the information of the relative distribution of the $\mathrm{SO}_{2}$ total emissions in the time- and altitude-dependent ini- 

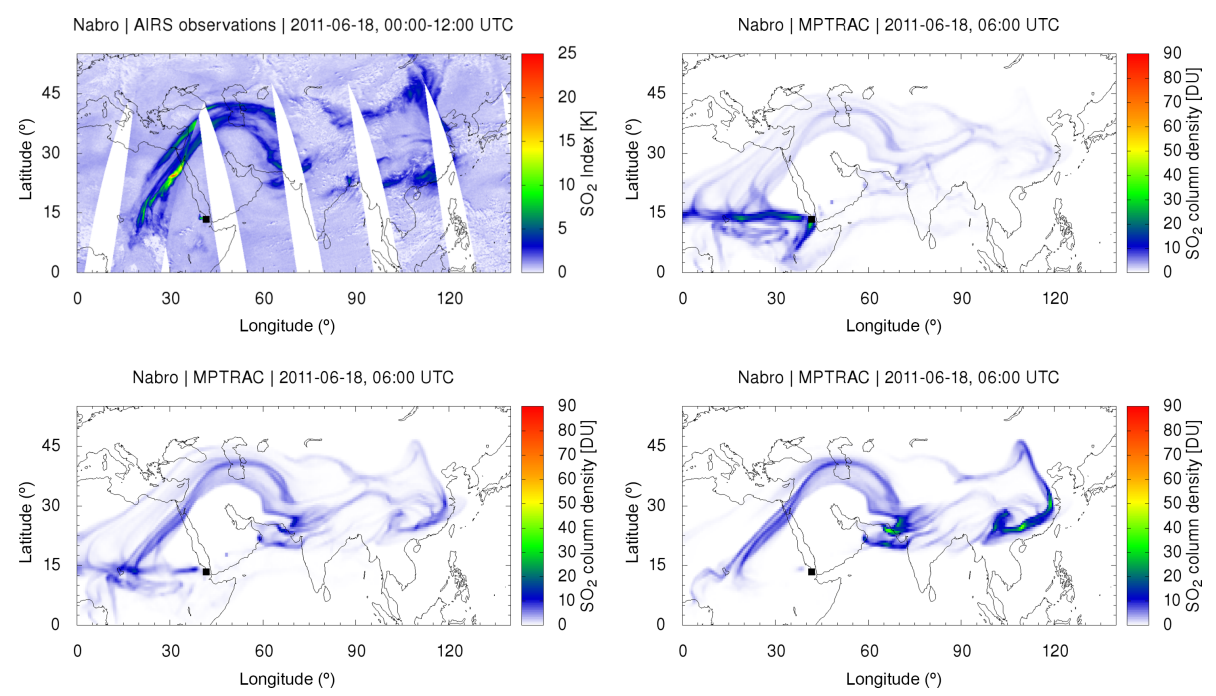

Figure 15. Same as Fig. 11, but for 18 June 2011, 06:00 UTC.
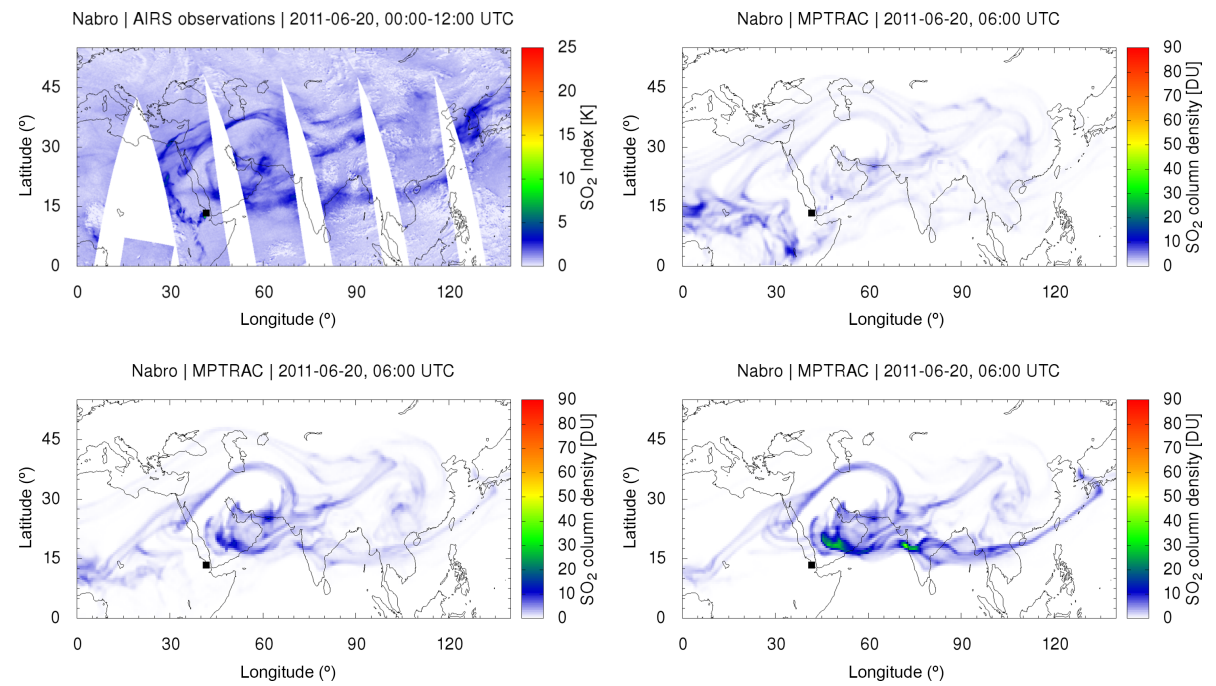

Figure 16. Same as Fig. 11, but for 20 June 2011, 06:00 UTC.

tialization domain, which is estimated by the proposed inversion algorithm, the local $\mathrm{SO}_{2}$ emission rates can be obtained.

Together with the equal-probability assumption, two weight-updating schemes, referred to as the mean rule and product rule have been proposed for the reconstruction of emission data. Considering the Nabro eruption in June 2011 as a case study, we qualitatively assessed the reconstructed emission time series by comparing them with Meteosat-7 (IODC) imagery to validate the temporal development and with CALIOP and MIPAS satellite observations to confirm the injection altitudes. Simulation results based on the initializations reconstructed by different weight-updating schemes have been compared, in particular, to demonstrate the advantages of the product rule. The mean and maximum CSI values obtained by using the equal-probability strategy are 8.1 and $32.3 \%$, respectively. The mean rule yields a mean CSI value of $16.6 \%$ and a maximum of $41.2 \%$. The product rule leads to an improvement of the mean CSI value to $21.4 \%$ and of the maximum CSI value to $52.4 \%$. The simulation results for the Nabro case study show good agreement with the AIRS satellite observations in terms of $\mathrm{SO}_{2}$ horizontal distributions and have been validated through other independent data sets such as IASI and GOME-2 satellite observations reported by other studies. The simulation results show that the inverse modeling system successfully identified the complex volcanic emission pattern of the Nabro eruption, and helped to further reveal the complex transport processes through the Asian monsoon circulation.

Some topics were explicitly excluded from this paper, but may be investigated in future work, including the extension 

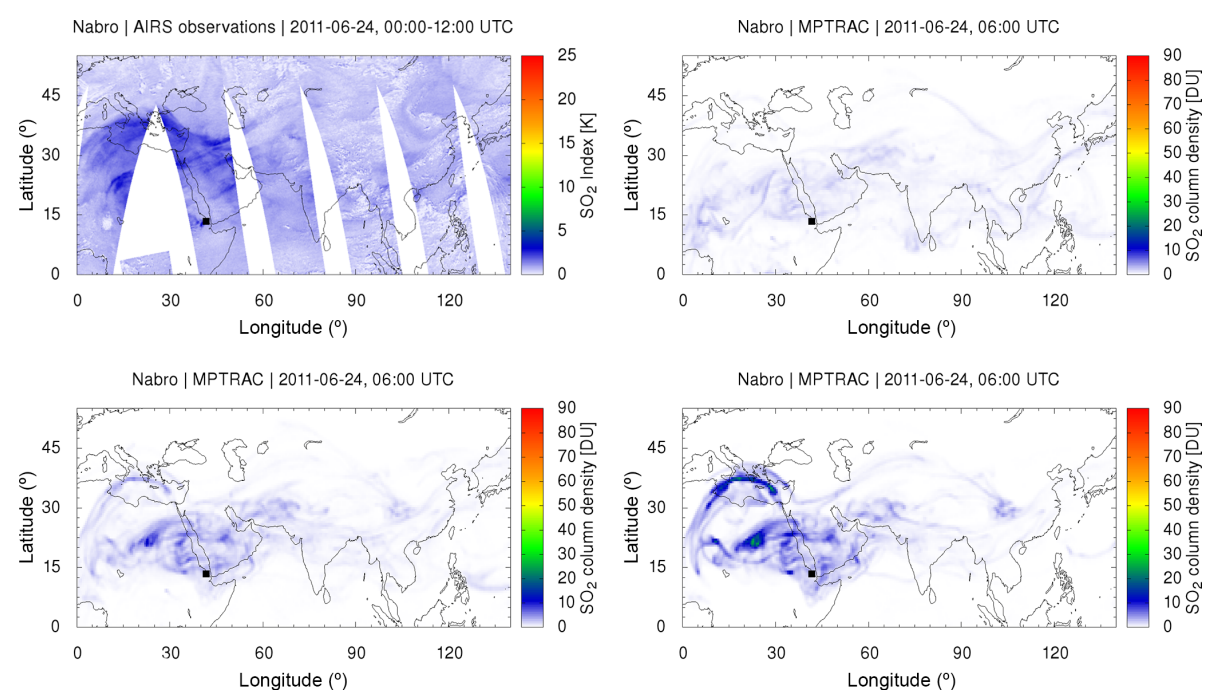

Figure 17. Same as Fig. 11, but for 24 June 2011, 06:00 UTC.

of the current approach towards near-real-time forecasting, the development of an adaptive strategy for discretizing the initialization domain, the consideration of the $\mathrm{SO}_{2}$ kernel functions, and a detailed treatment of data uncertainties. An adaptive strategy is expected to reduce the computational effort and to provide better resolution in areas of the initialization domain where there is large variability. This way, we would expect more precise importance weights estimated for the most likely cases of local emission and hence more accurate simulation results with better local details in a quantitative manner. In particular, the $\mathrm{SO}_{2}$ kernel functions of the AIRS channels used to calculate the SI depend on atmospheric conditions and altitude (e.g., Hoffmann et al., 2016, Fig. 1). However, variations in the UT/LS region where most of the Nabro emissions occurred are not too large. Hence, we did not consider this dependency in our analysis. However, the consideration of the AIRS kernel functions in the CSI analysis will be an important aspect in future work. Uncertainties in the meteorological data are another important source of error. The topic is addressed in a recent study by Hoffmann et al. (2016), wherein four different meteorological products have been tested for the MPTRAC simulations. This work aims to introduce an inversion approach for $\mathrm{SO}_{2}$ transport simulations. A more detailed, quantitative study of the errors resulting from the uncertainties of different meteorological data will be considered in future work. Furthermore, the version of MPTRAC used in this study did not consider loss processes of $\mathrm{SO}_{2}$. Hoffmann et al. (2016) used a newer version of MPTRAC, which takes into account loss processes of $\mathrm{SO}_{2}$. Although the simulation results by means of the two different versions of MPTRAC are rather similar, a precise quantitative analysis considering the $\mathrm{SO}_{2}$ loss will be subject of future efforts. Further research shall also be devoted to the testing of the proposed MPTRAC-based inverse modeling and simulation system for other case studies of volcanic eruptions and its capacity for forecasting.

\section{Code and data availability}

The current release of the MPTRAC model can be downloaded from the model web site at http://www.fz-juelich.de/ ias/jsc/mptrac. The code version used in this study can be obtained by contacting the corresponding author. The timeand altitude-dependent emission time series obtained with the different weight-updating schemes (Fig. 5) are provided as an electronic supplement to this paper. This allows our results to be reproduced and extended in future work, for instance by performing simulations with other transport models.

\section{The Supplement related to this article is available online at doi:10.5194/gmd-9-1627-2016-supplement.}

Acknowledgements. AIRS data products were obtained from the NASA Goddard Earth Sciences Data Information and Services Center (GES DISC). ERA-Interim data were obtained from the European Centre for Medium-Range Weather Forecasts (ECMWF). The authors gratefully acknowledge the computing time granted on the supercomputer JuRoPA at the Jülich Supercomputing Centre (JSC).

The article processing charges for this open-access publication were covered by a Research Centre of the Helmholtz Association.

Edited by: I. Pisso 


\section{References}

Aumann, H. H., Chahine, M. T., Gautier, C., Goldberg, M. D., Kalnay, E., McMillin, L. M., Revercomb, H., Rosenkranz, P. W., Smith, W. L., Staelin, D. H., Strow, L. L., and Susskind, J.: AIRS/AMSU/HSB on the Aqua Mission: design, science objectives, data products, and processing systems, IEEE T. Geosci. Remote, 41, 253-264, 2003.

Bourassa, A. E., Robock, A., Randel, W. J., Deshler, T., Rieger, L. A., Lloyd, N. D., Llewellyn, E. J. T., and Degenstein, D. A.: Large Volcanic Aerosol Load in the Stratosphere Linked to Asian Monsoon Transport, Science, 337, 78-81, 2012.

Brenot, H., Theys, N., Clarisse, L., van Geffen, J., van Gent, J., Van Roozendael, M., van der A, R., Hurtmans, D., Coheur, P.-F., Clerbaux, C., Valks, P., Hedelt, P., Prata, F., Rasson, O., Sievers, K., and Zehner, C.: Support to Aviation Control Service (SACS): an online service for near-real-time satellite monitoring of volcanic plumes, Nat. Hazards Earth Syst. Sci., 14, 1099-1123, doi:10.5194/nhess-14-1099-2014, 2014.

Carn, S. A., Krueger, A. J., Krotkov, N. A., Yang, K., and Evans, K.: Tracking volcanic sulfur dioxide clouds for aviation hazard mitigation, Nat. Hazards, 51, 325-343, 2009.

Casadevall, T. J.: The 1989-1990 eruption of Redoubt Volcano, Alaska: impacts on aircraft operations, J. Volcanol. Geoth. Res., 62, 301-316, 1994.

Chahine, M. T., Pagano, T. S., Aumann, H. H., Atlas, R., Barnet, C., Blaisdell, J., Chen, L., Divakarla, M., Fetzer, E. J., Goldberg, M., Gautier, C., Granger, S., Hannon, S., Irion, F. W., Kakar, R., Kalnay, E., Lambrigtsen, B. H., Lee, S., Marshall, J. L., McMillan, W. W., McMillin, L., Olsen, E. T., Revercomb, H., Rosenkranz, P., Smith, W. L., Staelin, D., Strow, L. L., Susskind, J., Tobin, D., Wolf, W., and Zhou, L.: AIRS: improving weather forecasting and providing new data on greenhouse gases, B. Am. Meteorol. Soc., 87, 911-926, 2006.

Clarisse, L., R'Honi, Y., Coheur, P.-F., Hurtmans, D., and Clerbaux, C.: Thermal infrared nadir observations of 24 atmospheric gases, Geophys. Res. Lett., 38, L10802, doi:10.1029/2011GL047271, 2011.

Clarisse, L., Hurtmans, D., Clerbaux, C., Hadji-Lazaro, J., Ngadi, Y., and Coheur, P.-F.: Retrieval of sulphur dioxide from the infrared atmospheric sounding interferometer (IASI), Atmos. Meas. Tech., 5, 581-594, doi:10.5194/amt-5-581-2012, 2012.

Clarisse, L., Coheur, P.-F., Prata, F., Hadji-Lazaro, J., Hurtmans, D., and Clerbaux, C.: A unified approach to infrared aerosol remote sensing and type specification, Atmos. Chem. Phys., 13, 21952221, doi:10.5194/acp-13-2195-2013, 2013.

Clarisse, L., Coheur, P.-F., Theys, N., Hurtmans, D., and Clerbaux, C.: The 2011 Nabro eruption, a $\mathrm{SO}_{2}$ plume height analysis using IASI measurements, Atmos. Chem. Phys., 14, 3095-3111, doi:10.5194/acp-14-3095-2014, 2014.

Clerbaux, C., Boynard, A., Clarisse, L., George, M., Hadji-Lazaro, J., Herbin, H., Hurtmans, D., Pommier, M., Razavi, A., Turquety, S., Wespes, C., and Coheur, P.-F.: Monitoring of atmospheric composition using the thermal infrared IASI/MetOp sounder, Atmos. Chem. Phys., 9, 6041-6054, doi:10.5194/acp-9-6041-2009, 2009.

Dee, D. P., Uppala, S. M., Simmons, A. J., Berrisford, P., Poli, P., Kobayashi, S., Andrae, U., Balmaseda, M. A., Balsamo, G., Bauer, P., Bechtold, P., Beljaars, A. C. M., van de Berg, L., Bidlot, J., Bormann, N., Delsol, C., Dragani, R., Fuentes, M.,
Geer, A. J., Haimberger, L., Healy, S. B., Hersbach, H., Hólm, E. V., Isaksen, L., Kãllberg, P., Köhler, M., Matricardi, M., McNally, A. P., Monge-Sanz, B. M., Morcrette, J.-J., Park, B.K., Peubey, C., de Rosnay, P., Tavolato, C., Thépaut, J.-N., and Vitart, F.: The ERA-Interim reanalysis: configuration and performance of the data assimilation system, Q. J. Roy. Meteor. Soc., 137, 553-597, 2011.

Del Moral, P.: Non Linear Filtering: Interacting Particle Solution, Markov Processes and Related Fields, 2, 555-580, 1996.

Draxler, R. R. and Hess, G. D.: An overview of the HYSPLIT_4 modeling system of trajectories, dispersion, and deposition, Aust. Meteorol. Mag., 47, 295-308, 1998.

Eckhardt, S., Prata, A. J., Seibert, P., Stebel, K., and Stohl, A.: Estimation of the vertical profile of sulfur dioxide injection into the atmosphere by a volcanic eruption using satellite column measurements and inverse transport modeling, Atmos. Chem. Phys., 8, 3881-3897, doi:10.5194/acp-8-3881-2008, 2008.

Fischer, H., Birk, M., Blom, C., Carli, B., Carlotti, M., von Clarmann, T., Delbouille, L., Dudhia, A., Ehhalt, D., Endemann, M. Flaud, J. M., Gessner, R., Kleinert, A., Koopman, R., Langen, J., López-Puertas, M., Mosner, P., Nett, H., Oelhaf, H., Perron, G., Remedios, J., Ridolfi, M., Stiller, G., and Zander, R.: MIPAS: an instrument for atmospheric and climate research, Atmos. Chem. Phys., 8, 2151-2188, doi:10.5194/acp-8-2151-2008, 2008.

Flemming, J. and Inness, A.: Volcanic sulfur dioxide plume forecasts based on UV satellite retrievals for the 2011 Grímsvötn and the 2010 Eyjafjallajökull eruption, J. Geophys. Res., 118, 1017210189, 2013

Fromm, M., Nedoluha, G., and Charvát, Z.: Comment on "Large Volcanic Aerosol Load in the Stratosphere Linked to Asian Monsoon Transport", Science, 339, p. 647, doi:10.1126/science.1228605, 2013.

Fromm, M., Kablick III, G., Nedoluha, G., Carboni, E., Grainger, R., Campbell, J., and Lewis, J.: Correcting the record of volcanic stratospheric aerosol impact: Nabro and Sarychev Peak, J. Geophys. Res., 119, 10343-10364, 2014.

Gordon, N. J., Salmond, D. J., and Smith, A. F. M.: Novel approach to nonlinear/non-Gaussian Bayesian state estimation, IEE Proceedings F (Radar and Signal Processing), 140, 107-113, 1993.

Griessbach, S., Hoffmann, L., von Hobe, M., Müller, R., Spang, R. and Riese, M.: A six-year record of volcanic ash detection with Envisat MIPAS, in: Proceedings of ESA ATMOS 2012, European Space Agency, ESA Special Publication SP-708 (CDROM), 2012.

Griessbach, S., Hoffmann, L., Spang, R., and Riese, M.: Volcanic ash detection with infrared limb sounding: MIPAS observations and radiative transfer simulations, Atmos. Meas. Tech., 7, 14871507, doi:10.5194/amt-7-1487-2014, 2014.

Griessbach, S., Hoffmann, L., Spang, R., von Hobe, M., Müller, R., and Riese, M.: Infrared limb emission measurements of aerosol in the troposphere and stratosphere, Atmos. Meas. Tech. Discuss., 8, 4379-4412, doi:10.5194/amtd-8-4379-2015, 2015.

Harvey, N. J. and Dacre, H. F.: Spatial evaluation of volcanic ash forecasts using satellite observations, Atmos. Chem. Phys., 16, 861-872, doi:10.5194/acp-16-861-2016, 2016.

Hilton, F., Armante, R., August, T., Barnet, C., Bouchard, A., Camy-Peyret, C., Capelle, V., Clarisse, L., Clerbaux, C., Coheur, P.-F., Collard, A., Crevoisier, C., Dufour, G., Edwards, D., Faijan, F., Fourrié, N., Gambacorta, A., Goldberg, M., 
Guidard, V., Hurtmans, D., Illingworth, S., Jacquinet-Husson, N., Kerzenmacher, T., Klaes, D., Lavanant, L., Masiello, G., Matricardi, M., McNally, A., Newman, S., Pavelin, E., Payan, S., Péquignot, E., Peyridieu, S., Phulpin, T., Remedios, J., Schlüssel, P., Serio, C., Strow, L., Stubenrauch, C., Taylor, J., Tobin, D., Wolf, W., and Zhou, D.: Hyperspectral Earth Observation from IASI: Five Years of Accomplishments, Bull. Amer. Meteor. Soc., 93, 347-370, 2012.

Hoffmann, L. and Alexander, M. J.: Retrieval of stratospheric temperatures from Atmospheric Infrared Sounder radiance measurements for gravity wave studies, J. Geophys. Res., 114, D07105, doi:10.1029/2008JD011241, 2009.

Hoffmann, L. and Alexander, M. J.: Occurrence frequency of convective gravity waves during the North American thunderstorm season, J. Geophys. Res., 115, D20111, doi:10.1029/2010JD014401, 2010.

Hoffmann, L., Griessbach, S., and Meyer, C. I.: Volcanic emissions from AIRS observations: detection methods, case study, and statistical analysis, Proc. SPIE, 9242, 924214-924214-8, doi:10.1117/12.2066326, 2014.

Hoffmann, L., Rößler, T., Griessbach, S., Heng, Y., and Stein, O.: Lagrangian transport simulations of volcanic sulfur dioxide emissions: impact of meteorological data products, J. Geophys. Res.-Atmos., 121, doi:10.1002/2015JD023749, 2016.

Jones, A., Thomson, D., Hort, M., and Devenish, B.: Volcanic emissions from AIRS observations: The UK Met Office's nextgeneration atmospheric dispersion model, NAME III, in Air Pollution Modeling and its Application XVII, 580-589, Springer, 2007.

Karagulian, F., Clarisse, L., Clerbaux, C., Prata, A. J., Hurtmans, D., and Coheur, P. F.: Detection of volcanic $\mathrm{SO}_{2}$, ash, and $\mathrm{H}_{2} \mathrm{SO}_{4}$ using the Infrared Atmospheric Sounding Interferometer (IASI), J. Geophys. Res., 115, D00L02, doi:10.1029/2009JD012786, 2010.

Kristiansen, N. I., Stohl, A., Prata, A. J., Bukowiecki, N., Dacre, H., Eckhardt, S., Henne, S., Hort, M. C., Johnson, B. T., Marenco, F., Neininger, B., Reitebuch, O., Seibert, P., Thomson, D. J., Webster, H. N., and Weinzierl, B.: Performance assessment of a volcanic ash transport model mini-ensemble used for inverse modeling of the 2010 Eyjafjallajökull eruption, J. Geophys. Res., 117, D00U11, doi:10.1029/2011JD016844, 2012.

Kristiansen, N. I., Prata, A. J., Stohl, A., and Carn, S. A.: Stratospheric volcanic ash emissions from the 13 February 2014 Kelut eruption, Geophys. Res. Lett., 42, 588-596, 2015.

Lacasse, C., Karlsdóttir, S., Larsen, G., Soosalu, H., Rose, W., and Ernst, G.: Weather radar observations of the Hekla 2000 eruption cloud, Iceland, B. Volcanol., 66, 457-473, 2004.

Lamb, H. H.: Volcanic dust in the atmosphere, with a chronology and assessment of its meteorological significance, Philos. T. Roy. Soc. A, 266, 425-533, 1970.

Moxnes, E. D., Kristiansen, N. I., Stohl, A., Clarisse, L., Durant, A., Weber, K., and Vogel, A.: Separation of ash and sulfur dioxide during the 2011 Grímsvötn eruption, J. Geophys. Res., 119, 7477-7501, doi:10.1002/2013JD021129, 2014.

Munro, R., Eisinger, M., Anderson, C., Callies, J., Corpaccioli, E., Lang, R., Lefebvre, A., Livschitz, Y., and Albinana, A. P.: GOME-2 on MetOp, in: Proceedings of The 2006 EUMETSAT Meteorological Satellite Conference, Helsinki, Finland, 1216 June 2006, EUMETSAT p. 48, 2006.
Prata, A. J.: Satellite detection of hazardous volcanic clouds and the risk to global air traffic, Nat. Hazards, 51, 303-324, 2009.

Raspollini, P., Carli, B., Carlotti, M., Ceccherini, S., Dehn, A., Dinelli, B. M., Dudhia, A., Flaud, J.-M., López-Puertas, M., Niro, F., Remedios, J. J., Ridolfi, M., Sembhi, H., Sgheri, L., and von Clarmann, T.: Ten years of MIPAS measurements with ESA Level 2 processor V6 - Part 1: Retrieval algorithm and diagnostics of the products, Atmos. Meas. Tech., 6, 2419-2439, doi:10.5194/amt-6-2419-2013, 2013.

Robock, A.: Volcanic eruptions and climate, Rev. Geophys., 38, 191-219, 2000.

Schaefer, J. T.: The critical success index as an indicator of warning skill, Weather Forecast., 5, 570-575, 1990.

Sears, T. M., Thomas, G. E., Carboni, E. A., Smith, A. J., and Grainger, R. G.: $\mathrm{SO}_{2}$ as a possible proxy for volcanic ash in aviation hazard avoidance, J. Geophys. Res., 118, 5698-5709, 2013.

Seibert, P.: Inverse modelling of sulfur emissions in Europe based on trajectories, in: Inverse Methods in Global Biogeochemical Cycles, edited by: Kasibhatla, P., Heimann, M., Rayner, P., Mahowald, N., Prinn, R. G., and Hartley, D. E., Geophysical Monograph 114, American Geophysical Union, ISBN-10: 0-87590097-6, Washington DC, USA, 147-154, 2000.

Solomon, S., Daniel, J. S., Neely, R., Vernier, J.-P., Dutton, E. G., and Thomason, L. W.: The persistently variable "background" stratospheric aerosol layer and global climate change, Science, 333, 866-870, 2011.

Stein, O., Flemming, J., Inness, A., Kaiser, J. W., and Schultz, M. G.: Global reactive gases forecasts and reanalysis in the MACC project, J. Integr. Environ. Sci., 9, 57-70, 2012.

Stohl, A., Forster, C., Frank, A., Seibert, P., and Wotawa, G.: Technical note: The Lagrangian particle dispersion model FLEXPART version 6.2, Atmos. Chem. Phys., 5, 2461-2474, doi:10.5194/acp-5-2461-2005, 2005.

Stohl, A., Prata, A. J., Eckhardt, S., Clarisse, L., Durant, A., Henne, S., Kristiansen, N. I., Minikin, A., Schumann, U., Seibert, P., Stebel, K., Thomas, H. E., Thorsteinsson, T., Tørseth, K., and Weinzierl, B.: Determination of time- and height-resolved volcanic ash emissions and their use for quantitative ash dispersion modeling: the 2010 Eyjafjallajökull eruption, Atmos. Chem. Phys., 11, 4333-4351, doi:10.5194/acp-11-4333-2011, 2011.

Stunder, B. J., Heffter, J. L., and Draxler, R. R.: Airborne volcanic ash forecast area reliability, Weath. Forecast, 22, 1132-1139, 2007.

Theys, N., Campion, R., Clarisse, L., Brenot, H., van Gent, J., Dils, B., Corradini, S., Merucci, L., Coheur, P.-F., Van Roozendael, M., Hurtmans, D., Clerbaux, C., Tait, S., and Ferrucci, F.: Volcanic $\mathrm{SO}_{2}$ fluxes derived from satellite data: a survey using OMI, GOME-2, IASI and MODIS, Atmos. Chem. Phys., 13, 59455968, doi:10.5194/acp-13-5945-2013, 2013.

Tikhonov, A. N. and Arsenin, V. Y.: Solutions of Ill-posed Problems, V. H. Winston and Sons, Washington, ISBN-10: 0-47099124-0, 1977.

Vernier, J.-P., Thomason, L. W., Fairlie, T. D., Minnis, P., Palikonda, R., and Bedka, K. M.: Comment on "Large Volcanic Aerosol Load in the Stratosphere Linked to Asian Monsoon Transport", Science, 339, p. 647, doi:10.1126/science.1227817, 2013. 
Webley, P., Stunder, B., and Dean, K.: Preliminary sensitivity study of eruption source parameters for operational volcanic ash cloud transport and dispersion models - a case study of the August 1992 eruption of the Crater Peak vent, Mount Spurr, Alaska, J. Volcanol. Geotherm. Res., 186, 108-119, 2009.

Wernli, H. and Davies, H. C.: A Lagrangian-based analysis of extratropical cyclones, I: The method and some applications, Q. J. Roy. Meteor. Soc., 123, 467-489, 1997.
Winker, D. M., Pelon, J., Coakley, J. A., Ackerman, S. A., Charlson, R. J., Colarco, P. R., Flamant, P., Fu, Q., Hoff, R. M., Kittaka, C., Kubar, T. L., Le Treut, H., McCormick, M. P., Mégie, G., Poole, L., Powell, K., Trepte, C., Vaughan, M. A., and Wielicki, B. A.: The CALIPSO Mission: a global 3D view of aerosols and clouds, B. Am. Meteorol. Soc., 91, 1211-1229, 2010 . 